\title{
1 Blocking mitophagy does not improve fuel ethanol production in Saccharomyces
}

cerevisiae

3 Kevy Pontes Eliodório ${ }^{1}$, Gabriel Caetano de Gois e Cunha ${ }^{1}$, Brianna A White ${ }^{2}$, Demisha HM

4 Patel $^{2}$, Fangyi Zhang ${ }^{2}$, Ewald H Hettema ${ }^{2 *}$, Thiago Olitta Basso ${ }^{1}$, Andreas Karoly Gombert ${ }^{3}$,

$5 \quad$ Vijayendran Raghavendran ${ }^{2,4 *}$

$6{ }^{1}$ Department of Chemical Engineering, Escola Politécnica, University of São Paulo, Av. Prof.

7 Lineu Prestes, 580, 05424-970 São Paulo-SP, Brazil

$8 \quad{ }^{2}$ Department of Molecular Biology \& Biotechnology, University of Sheffield, Sheffield, S10

$9 \quad 2 \mathrm{TN}$, United Kingdom

$10{ }^{3}$ School of Food Engineering, University of Campinas, Rua Monteiro Lobato, 80, 13083-862

11 Campinas-SP, Brazil

$12{ }^{4}$ Current address: Department of Biology and Biological Engineering, Division of Industrial

13 Biotechnology, Kemivagen 10, Chalmers University of Technology, Gothenburg, SE 412 96,

14 Sweden

15

$16 *$ Corresponding authors

17

18 Applied and Environmental Microbiology

19 Keywords: Mitophagy, Fermentation, Mineral Medium, Yeast, Brazilian fuel ethanol 20 fermentation 


\section{Abstract}

23 Ethanol fermentation is frequently performed under conditions of low nitrogen. In

24 Saccharomyces cerevisiae, nitrogen limitation induces macroautophagy, including the 25 selective removal of mitochondria, also called mitophagy. Shiroma and co-workers (2014)

26 showed that blocking mitophagy by deletion of the mitophagy specific gene ATG32 increased

27 the fermentation performance during the brewing of Ginjo sake. In this study, we tested if a 28 similar strategy could enhance alcoholic fermentation in the context of fuel ethanol 29 production from sugarcane in Brazilian biorefineries. Conditions that mimic the industrial 30 fermentation process indeed induce Atg32-dependent mitophagy in cells of S. cerevisiae PE312 , a strain frequently used in the industry. However, after blocking mitophagy, no differences 32 in $\mathrm{CO}_{2}$ production, final ethanol titres or cell viability were observed after five rounds of 33 ethanol fermentation, cell recycling and acid treatment, as commonly performed in sugarcane 34 biorefineries. To test if $S$. cerevisiae's strain background influences this outcome, cultivations were carried out in a synthetic medium with strains PE-2, Ethanol Red (industrial) and BY

36 (laboratory), with and without a functional ATG32 gene, under oxic and oxygen restricted 37 conditions. Despite the clear differences in sugar consumption, cell viability and ethanol titres, among the three strains, we could not observe any improvement in fermentation performance related to the blocking of mitophagy. We conclude with caution that results

40 obtained with Ginjo sake yeast is an exception and cannot be extrapolated to other yeast 41 strains and that more research is needed to ascertain the role of autophagic processes during 42 fermentation.

Importance

45 Bioethanol is the largest (per volume) ever biobased bulk chemical produced globally. The 46 fermentation process is very well established, and industries regularly attain nearly $85 \%$ of 
47 maximum theoretical yields. However, because of the volume of fuel produced, even a small

48 improvement will have huge economic benefits. To this end, besides already implemented

49 process improvements, various free energy conservation strategies have been successfully

50 exploited at least in laboratory strains to increase ethanol yields and decrease by-product

51 formation. Cellular housekeeping processes have been an almost unexplored territory in

52 strain improvement. Shiroma and co-workers previously reported that blocking mitophagy by

53 deletion of the mitophagy receptor gene ATG32 in Saccharomyces cerevisiae led to a $2.12 \%$

54 increase in final ethanol titres during Japanese sake fermentation. We found in two

55 commercially used bioethanol strains (PE-2 and Ethanol Red) that ATG32 deficiency does

56 not lead to an improvement in cell viability or ethanol levels during fermentation with

57 molasses or in a synthetic complete medium. More research is required to ascertain the role

58 of autophagic processes during fermentation conditions. 


\section{Introduction}

60 High cellular viability and a good combination of product titre, yield and productivity are

61 vital for the success of a bioprocess delivering bulk chemicals such as fuel ethanol. World

62 bioethanol production is ca. 100 billion litres from corn, sugarcane, or wheat, using the

63 industrial workhorse Saccharomyces cerevisiae $(1,2)$. The fermentation yield defined as

64 grams of ethanol that can be obtained per gram of sugar is the most important parameter in this industrial process (3). In Brazil, decades of industrial practice and learning by doing have enabled the sugarcane biorefineries to achieve $\sim 85 \%$ of the theoretical maximum yield $(0.511$

$67 \mathrm{~kg}$ of bioethanol per $\mathrm{kg}$ of hexoses) (4). Devising strategies to produce more fuel ethanol per

68 hectare of land is challenging and requires nonconventional or breakthrough approaches. A

69 small increase in yield using a robust yeast would represent enormous economic and

70 environmental gains, due to the large volumes of bioethanol produced every year.

71 Bioethanol production can be described as a three-step process using large, non-aseptic tanks.

72 Firstly, the sugarcane juice/molasses is fed into large tanks that contain the yeast slurry

73 (prepared from the leftover of previous fermentations) and the mixture is allowed to ferment

74 for $\sim 10 \mathrm{~h}$; secondly, the fermented mixture is centrifuged to separate the yeast cells for use in

75 the next cycle; and thirdly, the separated yeasts are washed with acid for $1-2 \mathrm{~h}$ to reduce the

76 bacterial contamination, before they are utilised in a new fermentation cycle (5). Though the

77 basic steps are common to all bioethanol plants, the yeast strains which catalyse the 78 conversion of the sugars can be different in each biorefinery and accordingly several variants

79 have been isolated (6). Basso and co-workers (6) investigated the population dynamics of

80 yeasts in the industrial process to identify those strains that persist and dominate after several

81 hundred rounds of cell recycling. They revealed that the baker's yeast strains inoculated at

82 the beginning of each sugarcane crushing season were naturally substituted by so-called wild 
83 or indigenous strains, some of which present many desired properties, such as absence of

84 flocculation or foam formation. Very recently, it has been hypothesised that the biofuel

85 producing yeasts may have been co-opted from a pool of yeasts preadapted to sugarcane juice

86 fermentation in the cachaça industry, which in turn descend from wine yeast strains

87 Europeans brought to South America, shedding new light on the origin and on the persistence

88 and dominance of these wild yeasts (7).

89 Sugarcane juice/molasses do not have enough nitrogen for cell growth $(8,9)$. After a few

90 division cycles, in response to nutrient depletion or stress, cells will consume part of their

91 own contents in a process known as autophagy, to recycle nutrients, and in this process, some

92 mitochondria are also degraded in a selective manner to maintain quality control (10-12). But

93 minimal mitochondrial development is necessary for providing the cell with key metabolic

94 intermediates and components (13). The role of mitochondria during anaerobic fermentation

95 has not been given proper attention possibly because of glucose repression. In the presence of

96 glucose, several respiratory enzymes and mitochondrial cytochromes remain low, vastly

97 decreasing the occurrence of oxidative phosphorylation (14). Piggott and co-workers (15)

98 used the genome wide gene deletion collection of the S288C strain to identify deletion strains

99 with an advantage or a fitness defect over a 14-day period using synthetic grape juice. Strains

100 with a defect in autophagy or in the ubiquitin-proteasome pathway had a reduced fitness

101 indicating that genes that function in autophagy are required for optimal survival during

102 fermentation even in a nitrogen replete environment (15).

103 Blocking mitochondrial degradation, known as mitophagy, improved cell viability and

104 bioethanol yield, at least in the context of sake fermentation, which was achieved via

105 disruption of the ATG32 gene (16). When mitophagy is induced, the mitochondrial protein

$106 \operatorname{Atg} 32$ binds to the adaptor protein Atg11, that links to the autophagosome biogenesis 
107 machinery. Sections of mitochondria are engulfed by growing autophagosomes that

108 subsequently fuse with vacuoles. Inside the vacuole the mitochondria are then degraded (17,

109 18). To verify if an $A T G 32$ deficiency leads to better fermentation performance during

110 Brazilian sugarcane fermentations for fuel ethanol production, the S. cerevisiae PE-2 strain,

111 engineered to lack $A T G 32$, was cultivated in a scaled-down mimicked industrial process,

112 using molasses medium (5). Cells were assessed for their viability and bioethanol production

113 over five rounds of cell recycling including sulphuric acid treatment. To compare our

114 observations made using an industrial medium (molasses) and an industrial S. cerevisiae

115 strain (PE-2), we also used the chemically defined, synthetic complete (SC) medium and

116 carried out standard fermentation experiments over 10 days, with two additional S. cerevisiae

117 backgrounds: the laboratory BY strain and the industrial yeast strain, Ethanol Red.

\section{Materials and Methods}

\section{Microorganisms and maintenance}

120 Saccharomyces cerevisiae PE-2 was obtained from NCYC; BY strains from EUROSCARF,

121 and Ethanol $\operatorname{Red}^{\mathrm{TM}}$ was obtained from our in-house strain collection. Table 1 lists the 122 genotypes and their origin. Strains were stored as YPD + glycerol $(15 \%$ v/v $)$ stocks $\left(-80{ }^{\circ} \mathrm{C}\right)$.

123 Strains were routinely grown on YPD (Yeast extract $10 \mathrm{~g} \cdot \mathrm{L}^{-1}$, Peptone $20 \mathrm{~g} \cdot \mathrm{L}^{-1}$ and Dextrose

$\left.12420 \mathrm{~g} \cdot \mathrm{L}^{-1}\right)$. When solid medium was required agar $\left(20 \mathrm{~g} \cdot \mathrm{L}^{-1}\right)$ was added. Routine growth was 125 performed at $30{ }^{\circ} \mathrm{C}, 200 \mathrm{rpm}$.

126 Table 1: List of strains used in this study.

\begin{tabular}{llll}
\hline \hline Name & Relevant genotype & $\begin{array}{l}\text { Parental } \\
\text { strain }\end{array}$ & Origin \\
\hline YEH1075 & NA & PE-2 & NCYC \\
& & & 3233 \\
\hline YEH1169 & MDH1-GFP::KanMX & PE-2 & $\begin{array}{l}\text { This } \\
\text { study }\end{array}$ \\
\hline YEH1104 & atg32 $::$ NatMX; atg32 $:: H p h M X$ & PE-2 & This \\
\hline
\end{tabular}


127 NA - Not available.

\begin{tabular}{|c|c|c|c|}
\hline & & $\operatorname{atg} 32 \Delta$ & study \\
\hline YEH1170 & $\operatorname{atg} 32 \Delta::$ NatMX; atg32 $\Delta:: H p h M X ;$ MDH1-GFP::KanMX & $\begin{array}{l}\mathrm{PE}-2 \\
\text { atg32 }\end{array}$ & $\begin{array}{l}\text { This } \\
\text { study }\end{array}$ \\
\hline YEH1083 & NA & $\begin{array}{l}\text { Ethanol } \\
\text { Red }\end{array}$ & Lab stock \\
\hline YEH1105 & $\operatorname{atg} 32 \Delta:: \mathrm{NatMX} ; \operatorname{atg} 32 \Delta:: \mathrm{HphMX}$ & $\begin{array}{l}\text { Ethanol } \\
\text { Red } \operatorname{atg} 32 \Delta\end{array}$ & $\begin{array}{l}\text { This } \\
\text { study }\end{array}$ \\
\hline YEH1115 & 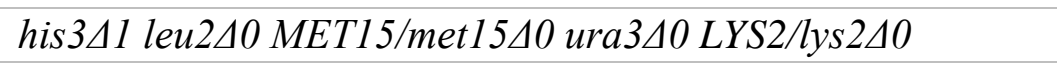 & BY4743 & Lab stock \\
\hline YEH1110 & 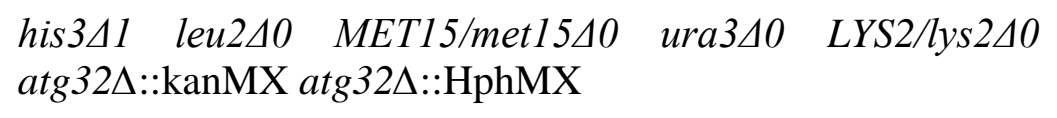 & $\begin{array}{l}\text { BY4743 } \\
\operatorname{atg} 32 \Delta\end{array}$ & $\begin{array}{l}\text { This } \\
\text { study }\end{array}$ \\
\hline YEH1172 & $\begin{array}{lccc}\text { MATa his3 } 41 \text { leu } 2 \Delta 0 \quad \text { met } 15 \Delta 0 \quad \text { ura3 } \Delta 0 & \text { MDH1- } \\
\text { GFP::HIS3MX6 atg } 32 \Delta:: \text { NatMX atg } 32 \Delta:: H p h M X & \end{array}$ & $\begin{array}{l}\mathrm{BY} 4743 \\
\operatorname{atg} 32 \Delta\end{array}$ & $\begin{array}{l}\text { This } \\
\text { study }\end{array}$ \\
\hline
\end{tabular}

Molecular biology techniques

130 Amplification of DNA cassettes were carried out using MyTaq DNA polymerase (Bioline

131 Reagents Ltd, UK) in a thermocycler with desalted oligonucleotide primers (Sigma-Aldrich,

132 UK) according to the manufacturer's protocol. S. cerevisiae was transformed with the

133 lithium-acetate method (19). Primers used in this study are listed in Table S1 (Supplementary

134 material). Single-cell lines of transformants were obtained by re-streaking on solid selective

135 medium.

\section{Strain construction}

137 Two copies of the ATG32 gene were mutated in Ethanol Red and PE-2 by replacing them

138 with selectable markers using a PCR based gene deletion method. The first copy of the

139 ATG32 open reading frame was replaced by the Klebsiella pneumoniae hygromycin B

140 phosphotransferase gene cassette (HphMX) that confers resistance to hygromycin B (20).

141 This cassette, present on pAG32, was amplified using primers VIP3915 and VIP3916 (Table

142 S1). Primers used for amplification contained $50 \mathrm{bp}$ flanks identical to the ATG32 ORF

143 upstream and downstream region to enable gene deletion via homologous recombination.

144 Transformed cells were plated onto YPD agar plates containing hygromycin B at a 
145 concentration of $300 \mu \mathrm{g} \cdot \mathrm{mL}^{-1}$. The NatMX cassette on plasmid p4339 (21) was amplified

146 using the same primers to replace the second ATG32 ORF. NatMX confers resistance to

147 nourseothricin (ClonNat, Werner Bioagents). Transformants were selected on YPD agar

148 plates containing $100 \mu \mathrm{g} \cdot \mathrm{mL}^{-1}$ ClonNat. Transformants were restreaked on selective medium

149 and total DNA was isolated from overnight YPD cultures using glassbeads/phenol-

150 chloroform extraction (22). Gene deletions were confirmed by PCR on total DNA. The

151 plasmids used in this study are mentioned in Table S2 (Supplementary material).

152 Deletion of ATG32 in the BY4743 strain was carried out in the haploid backgrounds 153 (BY4741 and BY4742) using NatMX and HphMX as selection markers. Diploids were

154 created by mating the strains and selecting on YPD plates containing both ClonNat and 155 hygromycin B.

156 To visualise mitochondria, Mdh1 was C-terminally tagged with GFP using a one-step PCR-

157 mediated protocol. The PCR fragment was generated using the primers VIP4045 and

158 VIP4046 using pFA6a-GFP(S65T)-kanMX and pFA6a-GFP(S65T)-HIS3MX6 as template

159 for PE-2 strains and BY4743 strains, respectively (23).

\section{Inoculum preparation}

161 A loopful of cells from a single colony on solid YPD-agar was inoculated into YPD (10 mL)

162 and grown for $17 \mathrm{~h}$ in an orbital shaker at $200 \mathrm{rpm}$ at $30{ }^{\circ} \mathrm{C}$. Cells were counted in a

163 Neubauer chamber using a phase contrast microscope at $400 \times$ magnification. The required

164 volume of culture liquid - corresponding to an initial optical density (600 nm) of 1.2 (Jenway

1656300 spectrophotometer) at the start of the propagation - was centrifuged, pellet resuspended

166 in sterile YPD or sterile synthetic complete medium (SC) (1 mL) and used as the inoculum

167 for batch fermentation. 
Fermentation experiments

169 The medium and the experimental set up used in this study are summarised in table 2.

170 Table 2: Experimental conditions used in this study.

\begin{tabular}{c|l|l}
\hline Cultivation & Setup & Medium + culture conditions \\
method & & \\
\hline $\mathbf{1}$ & Suba-Seal ${ }^{25}$ & \\
\hline $\mathbf{2}$ & $50 \mathrm{~mL}$ plastic centrifuge tube, loosely capped & Molasses, oxygen restricted, static, \\
\hline $\mathbf{3}$ & $50 \mathrm{~mL}$ plastic centrifuge tube, loosely capped & Synthetic complete medium, \\
\hline $\mathbf{4}$ & $8 \mathrm{~mL}$ Corning glass tubes loosely plastic & Synthetic medium, oxygen \\
& capped/ cotton stoppered $250 \mathrm{~mL}$ Erlenmeyer & restricted, $30^{\circ} \mathrm{C}$, static/Synthetic \\
\hline & flask & complete medium, $30{ }^{\circ} \mathrm{C}, 150 \mathrm{rpm}$ \\
& &
\end{tabular}

171

172 Fermentation with rich complex laboratory medium

173 Fermentation was carried out as described by Argueso and co-workers (24) on modified YPD

174 (yeast extract $5 \mathrm{~g} \cdot \mathrm{L}^{-1}$, peptone $10 \mathrm{~g} \cdot \mathrm{L}^{-1}$ and $100 \mathrm{~g} \cdot \mathrm{L}^{-1}$ glucose) in $25 \mathrm{~mL}$ Erlenmeyer flasks

175 (cultivation method 1) containing $15 \mathrm{~mL}$ of medium and stoppered with a Suba-Seal®

176 (Sigma Aldrich Inc.) septum to maintain oxygen restricted conditions. Cells were grown for

177 two cycles in the same medium to provide an adaptation round before using them as

178 inoculum for the fermentation experiments at a starting cell concentration of $10 \mathrm{mg}_{\mathrm{wet}}$

179 cells $\cdot \mathrm{mL}^{-1}$. Septa were pierced with two needles, one for sampling using a syringe, and another

180 one for the gas exit. Flasks were shaken at $175 \mathrm{rpm}$ in an orbital shaker at $30{ }^{\circ} \mathrm{C}$ to keep the

181 cells suspended. $\sim 0.5 \mathrm{~mL}$ samples were taken using a needle and a syringe every three hours, 
centrifuged $\left(12,000 g, 4{ }^{\circ} \mathrm{C}\right)$, supernatant stored at $-20{ }^{\circ} \mathrm{C}$, and wet pellet weighed to monitor the increase in cell mass over time.

\section{Fermentation mimicking the Brazilian sugarcane biorefinery}

185 Fermentation mimicking the Brazilian fermentation process was carried out as described 186 previously (5) using molasses from São Manuel mill (São Paulo, Brazil) as a substrate 187 (cultivation method 2). Briefly, $100 \mathrm{~g} \cdot \mathrm{L}^{-1}$ of molasses-grown wet cells were used to initiate 188 the fermentation using molasses containing total reducing sugars (TRS) of $140 \mathrm{~g} \cdot \mathrm{L}^{-1}$. 189 Approximately $4 \mathrm{~g}$ of wet cells were added to $50 \mathrm{~mL}$ centrifuge tubes and $27.75 \mathrm{~mL}$ 190 sugarcane molasses was added in three equivalent parts at 0,2 , and $4 \mathrm{~h}$ of fermentation, 191 mimicking the fed-batch process. The mass of $\mathrm{CO}_{2}$ lost was used as a proxy for the progress 192 of the fermentation. The temperature was controlled at $32^{\circ} \mathrm{C}$ in a static incubator, conditions typically encountered during industrial fuel ethanol production. After $10 \mathrm{~h}$, tubes were taken

194 out of the incubator and left on the bench at room temperature. After $20 \mathrm{~h}$, tubes were mixed 195 well, and $1 \mathrm{~mL}$ sample was taken for cell viability and metabolites analysis. The tubes were 196 then centrifuged, and the pelleted cells were resuspended in $6 \mathrm{~mL}$ of water, and $2 \mathrm{~mL}$ of the 197 wine (supernatant) from the previous cycle, and subjected to acid treatment $\left(\mathrm{H}_{2} \mathrm{SO}_{4}, 2 \mathrm{M}\right)$ for $1 \mathrm{~h}$ to a final $\mathrm{pH}$ of $\sim 2.5$ under static conditions before feeding was commenced with fresh molasses (5).

\section{$200 \quad$ Fermentation with mineral synthetic medium}

201 Mineral synthetic medium used in fermentation tests consisted of yeast nitrogen base

202 (Difco $\left.{ }^{\mathrm{TM}}\right)$ without amino acids $\left(1.7 \mathrm{~g} \cdot \mathrm{L}^{-1}\right)$, supplemented with ammonium sulphate $\left(5.0 \mathrm{~g} \cdot \mathrm{L}^{-}\right.$

$203^{1}$ ), complete supplement mixture Drop-out: Complete (Formedium, UK) $\left(790 \mathrm{mg} \cdot \mathrm{L}^{-1}\right)$, and 204 anhydrous glucose $\left(150 \mathrm{~g} \cdot \mathrm{L}^{-1}\right)$ in deionised water. Glucose was autoclaved separately. Batch sterilisation was carried out using the benchtop autoclave using factory settings. Before the 
start of the fermentation, $40 \mathrm{~mL}$ of $\mathrm{SC}$ medium were aliquoted in $50 \mathrm{~mL}$ Falcon tubes,

207 (Sarstedt), the tubes were sparged with $\mathrm{N}_{2}$ gas (BOC, UK, Oxygen Free Nitrogen, grade 5.0)

208 for 2 min using sterile needles (10 cm length) and inoculated with the cell suspension for a

209 start $\mathrm{OD}_{600}$ of 1.2. The tube caps were kept slightly loose to allow gas exit during the

210 fermentation and maintained under static conditions at $30{ }^{\circ} \mathrm{C}$ (cultivation method 3). Tubes

211 were weighed at time zero and then weighed every $24 \mathrm{~h}$ for 10 days to monitor mass loss

212 which is used as a proxy for the progress of the fermentation.

\section{Fermentation kinetics in synthetic medium}

214 In the experiment described in the above section, only end point sampling was made. To

215 study the kinetics of cell viability during the fermentation, another set of experiments was

216 conducted exactly as described above, but in $8 \mathrm{~mL}$ screw capped glass tubes (cultivation

217 method 4). Cells were inoculated to ten $8 \mathrm{~mL}$ screw capped glass tubes containing $6 \mathrm{~mL}$ of

218 SC medium (previously sparged with $\mathrm{N}_{2}$ ) and inoculated at the same OD as described above.

219 One tube was taken out each day and samples were taken for cell count and metabolites

220 analysis. Aerobic cultivations using SC medium were done in cotton stoppered $250 \mathrm{~mL}$

221 Erlenmeyer flasks (cultivation method 4) containing $50 \mathrm{~mL}$ medium and shaken at $150 \mathrm{rpm}$

222 in an orbital shaker. Samples $(1 \mathrm{~mL})$ were taken every $24 \mathrm{~h}$ for cell count and metabolites

223 determination.

\section{Mitophagy assays}

225 Under respiratory conditions, growth on a non-fermentable carbon source leads to the 226 proliferation of mitochondria. Thus, cells were grown overnight on YPglycerol (Yeast extract

$22710 \mathrm{~g} \cdot \mathrm{L}^{-1}$, Peptone $20 \mathrm{~g} \cdot \mathrm{L}^{-1}$ and glycerol $30 \mathrm{~g} \cdot \mathrm{L}^{-1}$ ) in long glass test tubes with plastic caps and 228 shifted to nitrogen starvation medium (Dextrose $20 \mathrm{~g} \cdot \mathrm{L}^{-1}$, yeast nitrogen base (Difco ${ }^{\mathrm{TM}}$ ) without amino acids and ammonium sulphate. During starvation, a substantial fraction of 
230 mitochondria are sequestered as cargoes and transported to the vacuole. Fluorescent marker

231 proteins used to monitor mitochondria can temporarily withstand the acidic conditions in the

232 vacuole and can be detected by immunoblotting as semi-quantitative evidence for mitophagy

$233(25)$.

234 For mitophagy assays on molasses (organic blackstrap molasses, Holland \& Barrett,

235 Meridian, UK), cells were grown overnight on YPD and shifted to molasses $\left(140 \mathrm{~g}_{\text {total-sugars }} \mathrm{L}^{-}\right.$

$236^{1}$ ) to an $\mathrm{OD}_{600}=1.2$ and incubated up to $44 \mathrm{~h}$. From this culture, $1.3 \mathrm{~g}$ of wet cell pellet was

237 transferred to $13 \mathrm{~mL}$ fresh molasses in a $15 \mathrm{~mL}$ falcon tube and incubated under oxygen

238 restricted conditions for $8 \mathrm{~h}$ and $24 \mathrm{~h}$ at $30{ }^{\circ} \mathrm{C}$. Cells were harvested and washed with water.

239 Some particulate debris was observed in the molasses grown cells due to the impurities

240 present in the molasses.

\section{$241 \quad$ Fluorescence imaging}

242 Live cells were analysed with an Axiovert 200M microscope (Carl Zeiss, Inc. Oberkochen,

243 Germany) equipped with Exfo X-cite 120 excitation light source (Excelitas technologies,

244 Waltham MA, USA), band-pass filters (Carl Zeiss, Inc., and Chroma, Bellow Falls VT,USA),

245 and a PlanFluar 100×/1.45 NA objective lens (Carl Zeiss, Inc.) and a digital camera (Orca

246 ER; Hamamatsu, Hamamatsu City, Japan). Image acquisition was performed using Volocity

247 software (PerkinElmer, Beaconsfield, UK). Fluorescence images were routinely collected as

$248 \quad 0.5 \mu \mathrm{m}$ Z-Stacks and merged into one plane using Openlab (PerkinElmer, Beaconsfield, UK)

249 and processed further in Photoshop (Adobe) where only the level adjustment was used.

250 Bright-field images were collected in a single plane and modified, so that only the

251 circumference of the cell was visible and pasted into the blue channel of Photoshop. 


\section{Western blot analysis}

253 For preparation of cell extracts by alkaline lysis, $10 \mathrm{OD}_{600}$ units of cells were harvested, and

254 pellets resuspended in $0.2 \mathrm{M} \mathrm{NaOH}$ and $0.2 \%(\mathrm{v} / \mathrm{v}) \beta$-mercaptoethanol and left on ice for 10

255 min. Soluble protein was precipitated by addition of trichloroacetic acid (5\% final 256 concentration $(\mathrm{w} / \mathrm{v})$ and left on ice for a further $10 \mathrm{~min}$. Following centrifugation $(13,000 \mathrm{~g}, 5$

257 min, $4{ }^{\circ} \mathrm{C}$ ), the pellet was resuspended in $10 \mu \mathrm{L}$ of $1 \mathrm{M}$ Tris-base and incubated at $95{ }^{\circ} \mathrm{C}$ in

$25890 \mu \mathrm{L} 1 \times$ SDS-PAGE sample loading buffer for $10 \mathrm{~min}$. Samples $\left(0.5 \mathrm{OD}_{600}\right.$ equivalent $)$

259 were resolved by $10 \%$ SDS-PAGE and transferred (BioRad Mini-Protean gel and transfer 260 system) to $0.45 \mu \mathrm{m}$ Nitrocellulose filters. Blots were blocked in $2 \%(\mathrm{w} / \mathrm{v})$ fat-free Marvel ${ }^{\mathrm{TM}}$ 261 milk in TBS-Tween 20 (50 mM Tris- $\mathrm{HCl}(\mathrm{pH} 7.5), 150 \mathrm{mM} \mathrm{NaCl}, 0.1 \%$ (v/v) Tween 20).

262 Proteins were detected using monoclonal anti-GFP (mouse; 1:3000; Roche 11814460001).

263 Secondary antibody was HRP-linked anti-mouse polyclonal (goat; 1:10000; Bio-Rad,

264 STAR207P). Detection was achieved using enhanced chemiluminescence (Biological

265 Industries, Kibbutz Beit Haemek, Israel) and chemiluminescence imaging using a Gbox from

266 Syngene (Synoptics Ltd, Cambridge, UK).

\section{Cell viability determination}

268 For experiments in SC medium, cellular viability was measured by plating out $100 \mu \mathrm{L}$ of 269 diluted samples on YPD (1:50, 1:1000, 1:5000 dilutions) and incubating them at $30{ }^{\circ} \mathrm{C}$ for 48

270 h. Colonies were manually counted to calculate the viable colony forming units (CFU) per $271 \mathrm{~mL}$. For experiments with molasses, counting of live/dead cells was performed as described 272 elsewhere (26).

\section{Flow cytometry analysis}

275 The forward scatter channel (FSC) and side scatter channel (SSC) measurements at the end of 276 each fermentation cycle of mimicked industrial fermentations were determined by flow 
277 cytometry. Flow cytometry analysis was performed by taking a $100 \mu \mathrm{L}$ sample from each

278 tube after fermentation had ceased $(20 \mathrm{~h})$. Samples were diluted 1000-fold in phosphate

279 buffers saline ( $\mathrm{pH} 7.4$ ), resulting in a final cell concentration of $\sim 10^{6}$ cells $\cdot \mathrm{mL}^{-1}$. The intensity

280 of the FSC and SSC readings were obtained using CytoFLEX flow cytometer (Beckman-

281 Coulter, USA), followed by post-acquisition performed in CytExpert analysis software

282 (Beckman-Coulter, USA). Cell counting was made with $30 \mu \mathrm{L}\left(\sim 10^{5}\right.$ cells $\cdot \mathrm{mL}^{-1}$.) of each 283 yeast suspension.

\section{Extracellular metabolites determination}

285 Glucose was analysed using the Megazyme GOPOD kit (K-GLUC 10/15, Megazyme Inc., 286 Ireland); ethanol was analysed using the Megazyme LQR kit (K-ETOH LQR, Megazyme 287 Inc., Ireland) using the manual assay procedure for large volumes (scaled down to half the 288 volume suggested in the manual) in a semi micro-cuvette. Substrate and metabolite 289 concentrations from molasses fermentation were determined by HPLC (Shimadzu 290 Prominence, Kyoto, Japan) using a refractive index detector. Samples were centrifuged and 291 filtered through $0.22 \mu \mathrm{m}$ pore size filter prior to injection. Sucrose, fructose, and glucose in samples from cultivations with molasses were separated with an Aminex ${ }^{\circledR}$ HPX-87C ionexchange column (Bio-Rad) at $85^{\circ} \mathrm{C}$, with ultrapure water as the mobile phase, at a flow rate

294 of $0.6 \mathrm{~L} \cdot \mathrm{min}^{-1}$. Ethanol and glycerol were analysed with an HPX-87H ion-exchange column 295 (BioRad) at $60{ }^{\circ} \mathrm{C}$ with sulphuric acid $(5 \mathrm{mM})$ at a flow rate of $0.6 \mathrm{~L} \cdot \mathrm{min}^{-1}$.

\section{Calculation of the maximum specific growth rate}

297 The maximum specific growth rate was obtained by plotting the natural logarithm of the 298 culture absorbance against time. The slope of the linear regression line represents the $\mu_{\max }$. 


\section{Statistical calculations}

300 Two sample $t$-test for assuming unequal variances (95\% confidence) was carried out in

301 Microsoft Excel 365 using the data Analysis Toolpak add-in (Microsoft Inc.).

\section{Results}

\section{Atg32 deficiency leads to the loss of mitophagy in the industrial strain S. cerevisiae PE-2}

304 Nitrogen starvation in laboratory yeast strains induces the selective autophagy of

305 mitochondria. During this process mitochondria are delivered to and degraded in vacuoles

306 (10). To monitor mitophagy we made use of the observation that GFP fusion proteins are 307 degraded upon entry into the vacuole but, since GFP is relatively resistant to vacuolar 308 degradation, GFP temporarily accumulates after delivery to the vacuole and its accumulation 309 can be used as a qualitative measure of autophagy (27). We tagged the mitochondrial malate 310 dehydrogenase (Mdh1) with GFP in the genome of S. cerevisiae PE-2 (strain YEH1169,

311 Table 1). These cells were grown on a nonfermentable carbon source (glycerol) before

312 transfer to low nitrogen, glucose medium. Upon shift to nitrogen starvation, we observed the 313 expected faint staining of a large subcellular structure, typical of the vacuole and a reduction 314 in the extensiveness of the mitochondrial network (Fig. 1A). These changes are dependent on 315 Atg32 and are in agreement with previous observations for S288c-derived strains $(17,18)$. In

316 addition, we also monitored Mdh1-GFP entry into vacuoles by western blot analysis using

317 antibodies against GFP. Mitochondrial GFP fusion proteins that enter the yeast vacuole are

318 cleaved and a relatively protease resistant GFP fragment accumulates temporarily that can be 319 detected with a GFP antiserum (10). Upon nitrogen starvation, the typical GFP fragment 320 indeed becomes apparent in PE-2 cells expressing Mdh1-GFP but not in cells deficient of 321 Atg32 (Fig. 1B). We conclude that Atg32 is required for mitophagy under nitrogen starvation 322 in the industrial strain PE-2. 
323 Subsequently, we tested whether PE-2 cells growing in molasses, which is known to be low

324 in nitrogen, induce mitophagy. Both in the presence of oxygen and during fermentation, cells

325 clearly display Atg32-dependent mitophagy (Fig.1C), albeit at a low level as no clear vacuole

326 labelling of Mdh1-GFP could be observed, but the mitochondrial network remained much

327 more extensive in PE-2 atg32 $\Delta$ cells compared to PE-2 cells (Fig. 1D).

\section{Deletion of the mitophagy receptor $A T G 32$ did not affect fermentation in rich medium}

329 To investigate if deleting the gene for a key cellular maintenance process affected growth

330 under nutrient abundant conditions, PE-2, Ethanol Red, and BY wildtype (WT) and atg32

331 S. cerevisiae were grown in standard YPD medium (see inoculum preparation) but using a

332 higher glucose concentration $\left(100 \mathrm{~g} \cdot \mathrm{L}^{-1}\right)$ under oxygen restricted conditions (cultivation

333 method 1). No difference was observed in the maximum specific growth rate or in the final

334 ethanol titres (Figure 2a and Figure 2b) between the WT and the atg32 $\Delta$ mutants during a

335 batch fermentation process. Ethanol Red exhibited the highest $\mu_{\max }$ (based on $\mathrm{OD}_{600}$ ) (WT:

$\left.3360.44 \pm 0.01 \mathrm{~h}^{-1} ; \operatorname{atg} 32 \Delta 0.45 \pm 0.00 \mathrm{~h}^{-1}\right)$, followed by PE-2 $\left(0.41 \pm 0.01 \mathrm{~h}^{-1}\right.$ for WT and

$337 \Delta a t g 32)$, and BY $\left(0.37 \pm 0.00 \mathrm{~h}^{-1}\right.$ for WT and $\left.\operatorname{atg} 32 \Delta\right)$. We further investigated the kinetic

338 performance of the $S$. cerevisiae PE-2 strain and its corresponding atg $32 \Delta$ mutant in a

339 similar medium than the one described above, but with less nitrogen $(0.5 \times \mathrm{YP}$, cultivation

340 method 1), also with $100 \mathrm{~g} / \mathrm{L}$ initial glucose, after acclimatising the cells for two days

341 aerobically (24). The results show that PE-2 WT and atg32 $\Delta$ behaved identically in terms of

342 biomass formation (Fig. 3a), sugar consumption and ethanol formation (Fig. 3b), reaching a

343 final ethanol concentration of $50 \mathrm{~g} \cdot \mathrm{L}^{-1}$ in $12 \mathrm{~h}$ (Fig. 3b). 
Fermentation performances of $S$. cerevisiae PE-2 and its corresponding atg32 $\Delta$ mutant

\section{in a mimicked scaled-down biorefinery do not differ}

346 Shiroma and co-workers (16) reported that blocking mitophagy improved the cell viability

347 and ethanol titres during simulated Japanese Ginjo sake fermentation. To investigate whether

348 the same strategy could improve fermentation performance under bioethanol production

349 conditions encountered in Brazilian sugarcane biorefineries, triplicate cultures of $S$.

cerevisiae PE-2 and of its isogenic atg32 $\Delta$ mutant were performed using diluted molasses

351 (obtained directly from a sugarcane refinery) as the cultivation medium, containing $140 \mathrm{~g} \cdot \mathrm{L}^{-1}$

352 of total sugars, in a scaled-down system that mimics the industrial process (cultivation

353 method 2)(5). Both the WT and the atg32 $\Delta$ strains behaved identically with respect to $\mathrm{CO}_{2}$

354 production - with a maximum $\mathrm{CO}_{2}$ of $2.0 \pm 0.0 \mathrm{~g}(\mathrm{WT})$ and $2.0 \pm 0.1$ (atg32 4 ) (Fig. 4a),

355 reaching a relative ethanol yield of $92.5 \pm 4.4 \%$ (WT) and $94.0 \pm 3.5 \%(\operatorname{atg} 32 \Delta)$ of the

356 maximum stoichiometric value of $0.511 \mathrm{~g}$ ethanol/g hexose, respectively (Fig. 4b), during

357 five rounds of cell recycling including acid wash between two consecutive rounds. The final

358 ethanol concentration reached was similar (WT: $56.0 \pm 2.0 \mathrm{~g} \cdot \mathrm{L}^{-1} ; \operatorname{atg} 32 \Delta: 56.7 \pm 1.6 \mathrm{~g} \cdot \mathrm{L}^{-1}$ )

359 and the cell viability remained extremely high through the five cycles for both strains (WT:

$36099.4 \pm 0.3 \%$; atg32 $4: 99.6 \pm 0.4 \%$ ). The glycerol concentration remained similar for all the

361 cycles (Fig. S1a, Supplementary Material) while yeast wet cell biomass was slightly higher in

362 the WT strain along the cycles as compared to the atg $32 \Delta$ mutant (Fig. S1b, Supplementary

363 Material). However, the biomass increase, or decrease was not significantly different when

364 the WT and the atg32 $\Delta$ mutant were compared. Cells accumulate trehalose under nutrient

365 starvation (28). Differences in trehalose accumulation were negligible (Fig. S1c,

366 Supplementary Material). The cell numbers at the end of each cycle were slightly higher for

$367 \operatorname{atg} 32 \Delta\left(565 \pm 20 \times 10^{6}\right.$ cells $\left.\cdot \mathrm{mL}^{-1}\right)$ throughout the five cycles tested compared to the WT

$368\left(583 \pm 20 \times 10^{6}\right.$ cells $\left.\cdot \mathrm{mL}^{-1}\right)($ Fig. S1d, Supplementary Material). 
369 Even though the absolute mass of wet cells (Fig. S1b, Supplementary Material) remained

370 lower for PE-2 atg32 $\Delta$ throughout the cell recycling process, the total cell concentration of

371 the PE-2 atg32 $\Delta$ strain was similar to that of WT. This is an indication of a reduced cellular

372 volume for PE-2 atg $32 \Delta$ as compared to the WT, which was corroborated by flow cytometry

373 data that revealed a lower mean forward scatter (FSC) for the atg32 $\Delta$ strain (Fig. S1e

374 Supplementary Material). This observation agrees with the deletion of the ATG32 gene in a

375 sake strain background during the production of Ginjo sake (16). Nevertheless, the rest of the

376 physiological parameters $\left(\mathrm{CO}_{2}\right.$, glycerol, ethanol, biomass, and trehalose), including the

377 ethanol yield, remained the same. It is likely that due to the low initial sugar concentration

378 employed, when compared to what is used industrially, the final ethanol titre $\left(57 \mathrm{~g} \cdot \mathrm{L}^{-1}\right)$

379 achieved is lower than what is typically encountered in Brazilian mills. Because the cell

380 viability remained extremely high at $98 \%$ throughout the five cycles, blocking mitophagy

381 does not improve fermentation performance under conditions encountered during industrial

382 fermentations for fuel ethanol production from sugarcane.

383 Strain background does not influence the fermentation performance of $S$. cerevisiae

384 atg32 $\Delta$ in a defined medium

385 As the deletion of the ATG32 gene did not result in increased process performance in the $S$. cerevisiae PE-2 strain, the influence of strain background was investigated, to see whether

387 this observation would hold for strain backgrounds different from PE-2. Because the cell

388 recycling experiments are laborious, we decided to conduct the experiments in a synthetic

389 medium (cultivation method 3) as described by Shiroma and co-workers (16). Cell viability

390 and $\mathrm{CO}_{2}$ production were compared between the laboratory BY strain, industrial PE-2, and

391 Ethanol Red S. cerevisiae together with their atg32 $\Delta$ counterparts in SC medium using 150

$392 \mathrm{~g} \cdot \mathrm{L}^{-1}$ glucose under static conditions. The $\mathrm{CO}_{2}$ profiles of the industrial WT strains of Ethanol 
393 Red, PE-2, and their atg32 4 counterparts, were indistinguishable (Fig. 5a), while the

394 laboratory BY strains had a lower rate of fermentation (Fig. 5a). Between days 0-2, 395 volumetric $\mathrm{CO}_{2}$ production increased rapidly for PE-2 $\left(29 \pm 2 \mathrm{~g} \cdot \mathrm{L}^{-1} \cdot\right.$ day $\left.^{-1}\right)$, Ethanol Red $(31 \pm$ $3964 \mathrm{~g} \cdot \mathrm{L}^{-1} \cdot$ day $\left.^{-1}\right)$, PE-2 $\operatorname{atg} 32 \Delta\left(33 \pm 2 \mathrm{~g} \cdot \mathrm{L}^{-1} \cdot\right.$ day $\left.^{-1}\right)$, and Ethanol Red $\operatorname{atg} 32 \Delta\left(33 \pm 1 \mathrm{~g} \cdot \mathrm{L}^{-1} \cdot\right.$ day $\left.^{-1}\right)$

397 and then decreased to $c a .3 .5 \mathrm{~g} \cdot \mathrm{L}^{-1} \cdot$ day $^{-1}$ between days 3-11. On the other hand, BY WT and 398 atg32 $\Delta$ strains exhibited a steady $\mathrm{CO}_{2}$ production until day four $\left(18 \pm 1 \mathrm{~g} \cdot \mathrm{L}^{-1} \cdot \mathrm{day}^{-1}\right), 1.8$-fold 399 lower than the industrial strains, after which it began to decrease between days $5-11$ to $2 \mathrm{~g} \cdot \mathrm{L}^{-}$

$400{ }^{1} \cdot$ day $^{-1}$. The culture $\mathrm{pH}$ at the end of 10 days was $\sim 2.8$ for all the strains. Cell viability was 401 measured at the end of 11 days and PE-2 cells failed to produce viable colonies in a rich YPD 402 medium (Fig. S2, Supplementary Material). However, the BY strains exhibited more CFUs 403 compared to Ethanol Red strains. To see if low pH or high sugar concentration encountered 404 during the fermentation affected growth, cells were plated on YPD at pH 2.5 and on $20 \%$ 405 glucose. The WT and atg32 $\Delta$ strains in all the three strain backgrounds exhibited remarkably 406 similar growth physiology (Fig. S3, Supplementary Material) during spot assays on YPD and 407 YP20D. PE-2 is known for its tolerance to low $\mathrm{pH}$, as it has been selected for decades to 408 withstand acid wash over multiple fermentation cycles in industry $(6,29)$. Ethanol Red WT 409 and atg32 $\Delta$ exhibited mild growth at the lowest cell concentration, and BY strains did not 410 grow. We can conclude that ATG32 deficiency did not improve the fermentation performance 411 in a defined medium in all the three strain backgrounds.

\section{Ability to ferment after re-pitching is strain dependent}

413 To test if the CFU counts reflected the metabolic vitality of cells in a liquid medium, cells

414 from the end of fermentation were re-pitched with fresh SC medium for a second round of 415 fermentation (30). Both Ethanol Red and BY strains were able to commence their 416 fermentation, albeit at a lower rate than the first cycle (Fig. 5b) but only after an initial lag of 
417 one day. The Brazilian yeast PE-2 struggled to ferment, and there was a big variation in the

$418 \mathrm{CO}_{2}$ production between the replicates, which is an indication of population heterogeneity, as

419 demonstrated for acetic acid tolerance by Swinnen and co-workers (31). $\mathrm{CO}_{2}$ production was

420 highest by day four after which it reached a plateau. Ethanol Red had the highest final $\mathrm{CO}_{2}$

421 production (WT: $83 \pm 6 \mathrm{~g} \cdot \mathrm{L}^{-1}$; atg $32 \Delta: 82 \pm 12 \mathrm{~g} \cdot \mathrm{L}^{-1}$ ), followed by BY (WT: $73 \pm 8 \mathrm{~g} \cdot \mathrm{L}^{-1}$;

atg32 $\left.4: 72 \pm 16 \mathrm{~g} \cdot \mathrm{L}^{-1}\right)$, and PE-2 (WT: $47 \pm 37 \mathrm{~g} \cdot \mathrm{L}^{-1} ; \operatorname{atg} 32 \Delta: 30 \pm 41 \mathrm{~g} \cdot \mathrm{L}^{-1}$ ) respectively.

Vast differences in the aerobic and oxygen restricted growth kinetics between

laboratory and industrial strains

425 To investigate the dramatic differences in viability between the three strains in their WT

426 backgrounds, they were cultured under oxic and oxygen restricted conditions in SC medium

427 to monitor the viability kinetics over 10 days (cultivation method 4). During oxygen

428 restricted conditions, the cell count increased between day 0 and 1 , but once ethanol started to

429 accumulate between days 1-6 the viable cell counts started to decrease steadily (Fig. 6a). The

$430 \log _{10}$ decrease in CFU. $\mathrm{mL}^{-1}$ was 1,1 , and 0.4 , for PE-2, Ethanol Red, and BY, respectively.

431 However, between days 6-10, BY performed remarkably well, exhibiting a $\log _{10}$ decrease of

432 0.6, while for PE-2 and Ethanol Red, it had dropped further to 2 and 1.1, respectively.

433 Glucose consumption was very rapid for PE-2 $\left(35 \pm 3 \mathrm{~g} \cdot \mathrm{L}^{-1} \cdot \mathrm{day}^{-1}\right)$ and Ethanol Red $(32 \pm 1$

$434 \mathrm{~g} \cdot \mathrm{L}^{-1} \cdot$ day $\left.^{-1}\right)$ compared to BY $\left(25 \pm 1 \mathrm{~g} \cdot \mathrm{L}^{-1} \cdot\right.$ day $\left.^{-1}\right)$ (Fig. 6b). By day 5 , all the glucose (150

$435 \mathrm{~g} \cdot \mathrm{L}^{-1}$ ) was exhausted for PE-2, while for Ethanol Red, and BY, the residual glucose

436 concentrations were $\sim 6$ and $36 \mathrm{~g} \cdot \mathrm{L}^{-1}$ respectively (Fig. 6b). The residual glucose for BY after

43710 days was $\sim 11 \mathrm{~g} \cdot \mathrm{L}^{-1}$. The final ethanol concentration reached were $79 \pm 6,79 \pm 9,72 \pm 3$

$438 \mathrm{~g} \cdot \mathrm{L}^{-1}$ for PE-2, Ethanol Red, and BY, respectively (Fig. 6c).

439 Unlike oxygen restricted conditions, the physiology of three yeast strains were remarkably

440 different than under aerobic conditions. The viable cell counts decreased steadily between 
day 2-6 for PE-2 and BY and between days 8-10, no viable colonies were observed. Ethanol

442 Red excelled among them and exhibited a $\log _{10}$ decrease in CFU of 1.5 between days 1-10

443 (Fig. 6d). PE-2 cells consumed glucose rapidly $\left(68 \pm 5 \mathrm{~g} \cdot \mathrm{L}^{-1} \cdot\right.$ day $\left.^{-1}\right)$ exhausting it by day 4

444 (Fig. 6e), while the rates were lower for Ethanol Red $\left(51 \pm 1 \mathrm{~g} \cdot \mathrm{L}^{-1} \cdot \mathrm{day}^{-1}\right)$ and BY $\left(21 \pm 2 \mathrm{~g} \cdot \mathrm{L}^{-}\right.$

$445{ }^{1} \cdot$ day $^{-1}$ ) (Fig. 6e). Also, glucose consumption stopped for Ethanol Red and BY from day 3, 446 reaching a steady state glucose level of $34 \pm 3 \mathrm{~g} \cdot \mathrm{L}^{-1}$ for Ethanol Red, and $115 \pm 12 \mathrm{~g} \cdot \mathrm{L}^{-1}$ for

447 BY (Fig. 6e). The final ethanol concentrations achieved were $58 \pm 2,40 \pm 1,23 \pm 4 \mathrm{~g} \cdot \mathrm{L}^{-1}$ for

448 PE-2, Ethanol Red and BY, respectively (Fig. 6f), lower than under oxygen restricted

449 conditions owing to increased biomass formation due to respiro-fermentative metabolism.

\section{Discussion}

451 High cell viability is vital for consistent cellular performance during bioproduction. The role

452 of cellular housekeeping processes as a target for strain improvement during fermentation is a

453 hitherto barely explored territory $(15,32-34)$. Shiroma and co-workers were the first in this

454 regard, blocking mitophagy and observing improved ethanol formation (12\% v/v for atg32

455 vs $11.75 \%$ v/v for WT BY4743) during Japanese sake fermentation (16). However, it should

456 be pointed out that this improvement was only observed under conditions of Ginjo sake

457 production and not under conditions of (conventional) sake production. Ginjo sake is

458 produced under more severe nutrient limitation, when compared to conventional sake

459 conditions, which is an indication that this limitation played an important role in the results

460 obtained by Shiroma et al (16). The mechanisms by which the improvements are brought

461 about have not been explored, but this increased ethanol production in the absence of

462 mitophagy could be related to a lack of recycled nutrients normally provided by mitophagy,

463 which cells use for biosynthesis. A combination of the absence of these internal building

464 blocks and the concomitant excess of the external carbon and energy source - the sugar in the 
cultivation medium - would channel more of this carbon towards the fermentative pathway

466 (36). In a different work, Jing and co-workers (35) report that deletion of ATG32 not only

467 decreased tolerance to ethanol stress in haploid BY 4742, but also led to a lower ethanol titre

$468(7.25 \% \mathrm{v} / \mathrm{v})$ compared to the WT $(7.5 \% \mathrm{v} / \mathrm{v})$ in standard YPD medium, which is nutrient rich.

469 For their ethanol measurement, they relied on densitometry, just like Shiroma and co-

470 workers, but this study used an enzymatic assay $(16,35)$. The improvement (or the decrease)

471 reported in these studies are quite marginal $(0.2 \% \mathrm{v} / \mathrm{v})$, and it beckons us to question whether

472 the accuracy of the measurement is reliable to claim physiological significance. It could also

473 be that if a higher number of experimental replicates had been performed by Shiroma et al

474 (16), no statistically significant difference would have been observed. In addition, the

475 different analytical techniques employed prevents direct comparison between studies of any

476 claims regarding the absolute ethanol titres. Morita and co-workers (36) report that deletion

477 of ATG32 increased the titres of 2,3-butanediol in engineered haploid BY4742 yeast, when

478 compared to the parental strain. However, these authors did not observe higher ethanol yields

479 or specific production rates in the atg32 mutant, with respect to the values displayed by the

480 parental strain, although deletion of $A T G 32$ significantly increased the maximum specific

481 growth rate. It should be noted that these experiments were performed using a commercial

482 synthetic yeast medium with $20 \mathrm{~g} / \mathrm{L}$ initial glucose, meaning that nutrient limitation is much

483 less prone to occur, when compared to the use of the same medium base, but with $150 \mathrm{~g} / \mathrm{L}$

484 initial glucose, as performed by Shiroma et al $(16,35,36)$.

485 When mitophagy was blocked in two different industrial strains, which were tested for their 486 performance in SC medium or using molasses in a scaled-down mimicked system, no

487 statistical difference in ethanol titres or viability was observed in our study. Only marginal 488 differences not related to fermentation performance were observed, such as a decreased cell 489 size in the mutant strain, that was also reported by Shiroma and co-workers (16). This 
highlights the fact that benefits accrued under one set of conditions for one strain may not necessarily be shared by another strain in a different cultivation environment. This has been exemplified by Rodrigues and co-workers (37), who show that the maximum specific growth rate on sucrose is higher than on glucose for one wild yeast isolate, whereas this is not the

494 case for other strains.

495 The three strains used in this study have vastly different origins. BY strain is a derivative of 496 S288C, whose progenitor EM93-IC was isolated from rotting fig in 1938 (38). It is routinely 497 propagated in the laboratory in YPD and SC medium. PE-2 was isolated from the Brazilian sugarcane fermentation industry (6). Ethanol Red is used extensively in the starch-based 499 ethanol industry (39). The viability data from the fermentation experiment on SC medium 500 (Fig 6a, 6d) corroborated the view that cells are adapted to their ecological niches and might 501 fare poorly in environments that are not optimal for their growth.

502 The BY strain harbours a mutation in the HAPl gene (40) that renders it sensitive to aerobic 503 growth. This could explain the retarded growth behaviour and the high residual glucose levels 504 observed under aerobic conditions (Fig 6e). HAPl encodes a heme-dependent transcription 505 regulator that controls the expression of genes involved in fermentation and ergosterol

506 biosynthesis (41). BY cells performed very well under oxygen restricted conditions, possibly 507 because of the absence of the repressor function of Hap1p $(41,42)$. BY strains which are 508 derived from S288C are reported to be a phenotypic extreme and its widespread use as a 509 norm for $S$. cerevisiae is a concern (43).

510 Despite these remarkable differences among the three strains investigated here, once 511 mitophagy was blocked via deletion of ATG32 in each background, no difference in

512 fermentation performance was observed between each reference strain and its corresponding 513 atg32 mutant. This clearly indicates that the results reported by Shiroma and co-workers (16) 
514 in the context of Ginjo sake fermentation cannot be extrapolated to other strain backgrounds

515 and/or conditions. Since we explored three different strain backgrounds and different

516 cultivation conditions, we caution that the benefits of blocking mitophagy for ethanol

517 formation in the context of Ginjo sake fermentations, if corroborated by future studies, are

518 peculiar to those conditions and not necessarily the rule.

\section{Author contributions}

520 VR carried out the strain characterisation and fermentation experiments; KPE, GCGC carried

521 out the cell recycling experiments; BAW, DHMP, FZ constructed the knockout strains; EHH

522 performed the Western blotting and fluorescence imaging. VR, TOB, AKG, EHH designed,

523 and planned the experiments. VR wrote the manuscript, and it was approved by all the co-

524 authors.

\section{Funding}

526 We thank BBSRC-KE funding (R/160337) for VR and Dr. Mikael Molin (Department of

527 Biology and Biological Engineering, Division of Systems Biology, Chalmers University of

528 Technology, Sweden) for providing feedback. TOB would like to acknowledge Fundação de

529 Amparo à Pesquisa do Estado de São Paulo (FAPESP) for grant 2018/17172-2. AKG would

530 like to acknowledge Fundação de Amparo à Pesquisa do Estado de São Paulo (FAPESP) for

531 grant 2017/08464-7 and Conselho Nacional de Desenvolvimento Científico e Tecnológico

532 (CNPq) for fellowships 307266/2019-2.

\section{References}

534 1. Jacobus AP, Gross J, Evans X, Cecatto-Antonini Sandra R, Gombert AK. 2021.

535 Saccharomyces cerevisiae strains used industrially for bioethanol production. Essays 
Biochem.

537 2. Eliodório KP, Cunha GC de G e, Müller C, Lucaroni AC, Giudici R, Walker GM, Alves SL, Basso TO. 2019. Chapter Three - Advances in yeast alcoholic fermentations for the production of bioethanol, beer and wine, p. 61-119. In Gadd, GM, Sariaslani, SBT-A in AM (eds.), . Academic Press.

541 3. Gombert AK, van Maris AJ. 2015. Improving conversion yield of fermentable sugars into fuel ethanol in 1st generation yeast-based production processes. Curr Opin Biotechnol 33:81-86.

544 4. Pereira RD, Rodrigues KCS, Sonego JLS, Cruz AJG, Badino AC. 2018. A new methodology to calculate the ethanol fermentation efficiency at bench and industrial scales. Ind Eng Chem Res 57:16182-16191.

547 5. Raghavendran V, Basso TP, da Silva JB, Basso LC, Gombert AK. 2017. A simple scaled down system to mimic the industrial production of first generation fuel ethanol in Brazil. Antonie Van Leeuwenhoek 110:1-13.

550 6. Basso LC, de Amorim H V, de Oliveira AJ, Lopes ML. 2008. Yeast selection for fuel ethanol production in Brazil. FEMS Yeast Res 8:1155-63.

552 7. Jacobus AP, Stephens TG, Youssef P, González-Pech R, Chen Y, Basso LC, Frazzon J, Chan CX, Gross J. 2021. Comparative genomics supports that Brazilian bioethanol Saccharomyces cerevisiae comprise a unified group of domesticated strains related to cachaça spirit yeasts. Front Microbiol 12:687.

556 8. Lino FS de O, Basso TO, Sommer MOA. 2018. A synthetic medium to simulate sugarcane molasses. Biotechnol Biofuels 11:221.

558 9. Walford S. 1996. Composition of cane juice. Proc South African Sugar Technol Assoc 70:265-266. 
560 10. Kanki T, Klionsky DJ. 2008. Mitophagy in yeast occurs through a selective mechanism. J Biol Chem 283:32386-32393.

11. Hoshida H, Kagawa S, Ogami K, Akada R. 2020. Anoxia-induced mitophagy in the yeast Kluyveromyces marxianus. FEMS Yeast Res 20:foaa057.

12. Tyler JK, Johnson JE. 2018. The role of autophagy in the regulation of yeast life span. Ann N Y Acad Sci 1418:31-43.

13. Šubík J, Kolarov J, Kováč L. 1972. Obligatory requirement of intramitochondrial ATP for normal functionning of the eucaryotic cell. Biochem Biophys Res Commun

14. O’Connor-Cox ESC, Lodolo EJ, Axcell BC. 1996. Mitochondrial relevance to yeast fermentative performance: A review. J Inst Brew 102:19-25.

15. Piggott N, Cook MA, Tyers M, Measday V, Walker ME, Nguyen TD, Liccioli T, Tyers M, Measday V. 2011. Genome-wide fitness profiles reveal a requirement for autophagy during yeast fermentation. Genes|Genomes|Genetics 15:353-67.

16. Shiroma S, Jayakody LN, Horie K, Okamoto K, Kitagaki H. 2014. Enhancement of ethanol fermentation in Saccharomyces cerevisiae sake yeast by disrupting mitophagy function. Appl Environ Microbiol 80:1002-12.

578 17. Kanki T, Wang K, Cao Y, Baba M, Klionsky DJ. 2009. Atg32 is a mitochondrial protein that confers selectivity during mitophagy. Dev Cell 17:98-109.

18. Okamoto K, Kondo-Okamoto N, Ohsumi Y. 2009. A landmark protein essential for mitophagy: Atg32 recruits the autophagic machinery to mitochondria. Autophagy 5:1203-5. 
stranded carrier DNA/polyethylene glycol method. Methods Enzymol https://doi.org/10.1016/S0076-6879(02)50957-5.

586

587

588

589

590

591

592

593

594

595

596

597

598

599

600

601

602

603

604

605

606

607

20. Goldstein AL, McCusker JH. 1999. Three new dominant drug resistance cassettes for gene disruption in Saccharomyces cerevisiae. Yeast 15:1541-53.

21. Tong AHY, Evangelista M, Parsons AB, Xu H, Bader GD, Pagé N, Robinson M, Raghibizadeh S, Hogue CWV, Bussey H, Andrews B, Tyers M, Boone C. 2001. Systematic genetic analysis with ordered arrays of yeast deletion mutants. Science (80) $294: 2364-8$.

22. Hoffman CS, Winston F. 1987. A ten-minute DNA preparation from yeast efficiently releases autonomous plasmids for transformaion of Escherichia coli. Gene https://doi.org/10.1016/0378-1119(87)90131-4.

23. Longtine MS, McKenzie A, Demarini DJ, Shah NG, Wach A, Brachat A, Philippsen P, Pringle JR. 1998. Additional modules for versatile and economical PCR-based gene deletion and modification in Saccharomyces cerevisiae. Yeast 14:953-61.

24. Argueso JL, Carazzolle MF, Mieczkowski PA, Duarte FM, Netto OVC, Missawa SK, Galzerani F, Costa GGL, Vidal RO, Noronha MF, Dominska M, Andrietta MGS, Andrietta SR, Cunha AF, Gomes LH, Tavares FCA, Alcarde AR, Dietrich FS, McCusker JH, Petes TD, Pereira GAG. 2009. Genome structure of a Saccharomyces cerevisiae strain widely used in bioethanol production. Genome Res 19:2258-70.

25. Kanki T, Kang D, Klionsky DJ. 2009. Monitoring mitophagy in yeast: the Om45-GFP processing assay. Autophagy 5:1186-9.

26. Smart KA, Chambers KM, Lambert I, Jenkins C, Smart CA. 1999. Use of methylene violet staining procedures to determine yeast viability and vitality. J Am Soc Brew Chem 57:18-23. 
608 27. Shintani T, Klionsky DJ. 2004. Autophagy in health and disease: A double-edged sword. Science (80- ) 306:990-5.

28. Panek A. 1963. Function of trehalose in Baker's yeast (Saccharomyces cerevisiae). Arch Biochem Biophys 100:422-425.

29. Della-bianca BE, Hulster E De, Pronk JT, Maris AJA Van, Gombert AK. 2014.

614 30. Kwolek-Mirek M, Zadrag-Tecza R. 2014. Comparison of methods used for assessing the viability and vitality of yeast cells. FEMS Yeast Res 14:1068-79.

31. Swinnen S, Fernández Niño M, González-Ramos D, van Maris AJ a., Nevoigt E. 2014. The fraction of cells that resume growth after acetic acid addition is a strain-dependent parameter of acetic acid tolerance in Saccharomyces cerevisiae. FEMS Yeast Res $14: 642-653$.

32. Cebollero E, Gonzalez R. 2007. Autophagy: From basic research to its application in food biotechnology. Biotechnol Adv 25:396-409.

33. Zhang J, Astorga MA, Gardner JM, Walker ME, Grbin PR, Jiranek V. 2018. wine yeast. Metab Eng 45:255-264.

34. Hu J, Dong Y, Wang W, Zhang W, Lou H, Chen Q. 2019. Deletion of ATG22 gene contributes to reduce programmed cell death induced by acetic acid stress in Saccharomyces cerevisiae. Biotechnol Biofuels 12:298. in yeast: regulation by mitochondrial reactive oxygen species in Saccharomyces cerevisiae. J Microbiol Biotechnol 30:1876-1884. 
mitochondrial metabolism for cytosolic pyruvate-derived chemical production in Saccharomyces cerevisiae. Microb Cell Fact 18:177.

634

37. Rodrigues CIS, Wahl A, Gombert AK. 2021. Aerobic growth physiology of Saccharomyces cerevisiae on sucrose is strain-dependent. FEMS Yeast Res 21.

38. Mortimer RK, Johnston JR. 1986. Genealogy of principal strains of the yeast genetic stock center. Genetics 113:35-43.

39. Demeke MM, Dumortier F, Li Y, Broeckx T, Foulquié-Moreno MR, Thevelein JM. Saccharomyces cerevisiae for efficient lignocellulose-based bioethanol production. Biotechnol Biofuels 6(1):120.

40. Gaisne M, Bécam AM, Verdière J, Herbert CJ. 1999. A "natural” mutation in Saccharomyces cerevisiae strains derived from S288c affects the complex regulatory gene HAP1 (CYP1). Curr Genet 36:195-200.

41. Tamura KI, Gu Y, Wang Q, Yamada T, Ito K, Shimoi H. 2004. A hapl mutation in a laboratory strain of Saccharomyces cerevisiae results in decreased expression of ergosterol-related genes and cellular ergosterol content compared to sake yeast. J Biosci Bioeng 98:159-66.

42. Hickman MJ, Winston F. 2007. Heme levels switch the function of Hap1 of Saccharomyces cerevisiae between transcriptional activator and transcriptional repressor. Mol Cell Biol 27:7414-7424. in yeast is defined by population history. PLOS Genet 7:e1002111. 
657 Figure 1: Mitophagy is blocked in S. cerevisiae PE-2 cells upon ATG32 deletion.

658 Mitophagy was assayed in S. cerevisiae PE-2 expressing Mdh1-GFP and isogenic atg32

659 cells grown overnight on nitrogen-rich glycerol medium (Gly N+) and shifted to glucose,

660 nitrogen starvation medium $(\mathrm{Glu} \mathrm{N}-)$ and incubated for $6 \mathrm{~h}$ at $30{ }^{\circ} \mathrm{C}(\mathrm{A}, \mathrm{B})$, or overnight on

661 YPD and shifted to molasses and incubated up to $44 \mathrm{~h}$. From this culture, cells were

662 transferred to fresh molasses and incubated under oxygen restricted conditions (molasses

663 fermentation, mol. ferm.) for $8 \mathrm{~h}$ and $24 \mathrm{~h}$ at $30^{\circ} \mathrm{C}(\mathrm{C}, \mathrm{D})$. Cells were imaged using

664 epifluorescence microscopy and Z stacks were merged into a single green image. Cell

665 circumference is stained blue (A, D). Note that upon nitrogen starvation (A), mitochondrial

666 structures are less abundant in PE-2 cells and instead a large diffusely stained organelle

667 becomes apparent (white arrow heads, vacuoles). A single focal plane near the centre of the

668 cell is shown to clearly illustrate the vacuolar staining. Although mitochondrial structures are

669 reduced in PE-2 cells in molasses compared to PE-2 atg32 $\Delta$ cells, no vacuolar labelling is

670 observed. Scale bar, $5 \mu \mathrm{m}$. (B, C) Western blot analysis of PE-2 and PE-2 atg32 $\triangle$ cell

671 samples using anti-GFP. GFP* indicates the relatively protease-resistant GFP-

672 degradation product indicative of vacuolar breakdown. An overexposed section of the

673 blot around GFP* is included (C). A Ponceau S staining of the filter was used as loading and

674 blotting control (B, C)

675

676 Figure 2: a) The maximum specific growth rate $\left(\mu_{\max }\right)$ and b) final ethanol titres during

677 oxygen restricted growth in YPD using $100 \mathrm{~g} \cdot \mathrm{L}^{-1}$ initial glucose. The dashed line in $1 \mathrm{~b}$

678 represents the maximum ethanol concentration that could be theoretically achieved. Filled 
679 columns represents the WT and open columns represents the atg32 $\Delta$ S. cerevisiae. Data 680 represent the mean and deviation from the mean $(n=2)$.

681 Figure 3: Kinetics of growth for the S. cerevisiae PE-2 strain and its isogenic atg32 $\triangle$ mutant 682 in $0.5 \times$ YPD and $100 \mathrm{~g} \cdot \mathrm{L}^{-1}$ initial glucose under oxygen restricted conditions. a) wet biomass 683 formation and b) sugar consumption and ethanol production. Datapoints represent the mean 684 and the error bars the standard deviation of three biological replicates $(n=3)$. Filled circles 685 represent the WT PE-2 and open circles represent atg32 $\Delta$ S. cerevisiae.

686 Figure 4: a) $\mathrm{CO}_{2}$ production and b) ethanol yields as \% maximum for S. cerevisiae PE-2 687 (WT) and its corresponding atg32 $\Delta$ mutant in diluted molasses medium in a scaled down and 688 mimicked process resembling Brazilian sugarcane fermentations. Filled circles/bars represent 689 the WT PE-2 and open circles represent atg32 $\Delta$ S. cerevisiae. Data represent the mean and 690 standard deviation of three technical replicates and the experiment was performed twice.

691 Figure 5: a) Time course of $\mathrm{CO}_{2}$ production for the WT and atg32 $\mathrm{S}$. cerevisiae in SC 692 medium using $150 \mathrm{~g} \cdot \mathrm{L}^{-1}$ glucose. b) Time course of $\mathrm{CO}_{2}$ production after re-pitching the 693 pelleted cells from 11 days of fermentation with $40 \mathrm{~mL}$ of SC medium. Open markers 694 represent the atg32 $\Delta$ strains and filled markers represent the WT strains; Ethanol Red is 695 depicted in red, PE-2 is green, and BY in blue. Data represent the mean and standard 696 deviation $(n=3)$.

697 Figure 6: Growth kinetics of PE-2, Ethanol Red and BY yeast in SC medium under oxygen 698 restricted and aerobic conditions. Oxygen restricted: a) CFU, b) glucose c) ethanol;

699 Aerobic: a) CFU, b) glucose c) ethanol. Ethanol Red is depicted in red, PE-2 is green, and 700 BY in blue. Data represent the mean and standard deviation $(n=3)$. 
A
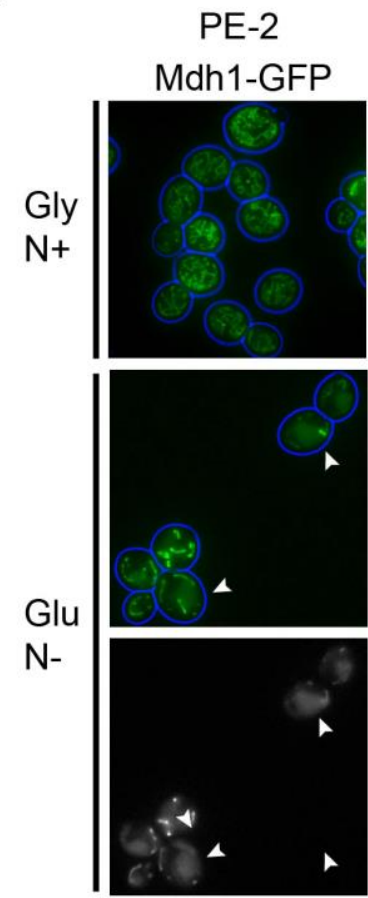

C

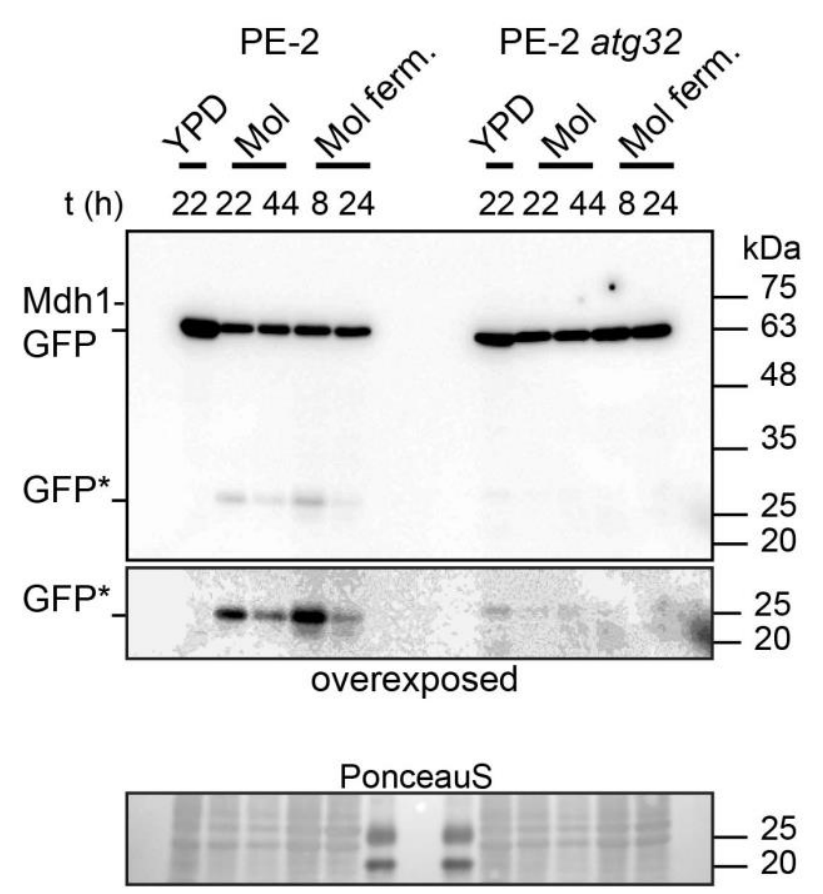

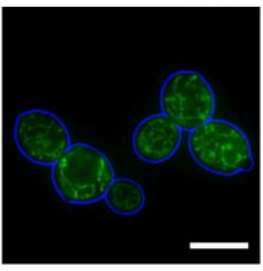

Mdh1-GFP

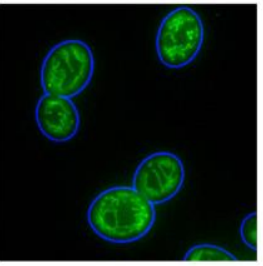

single focal plane
B

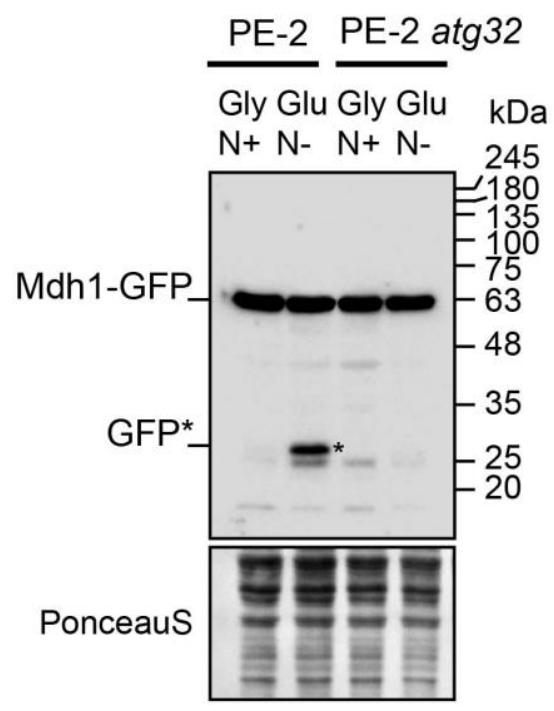

D

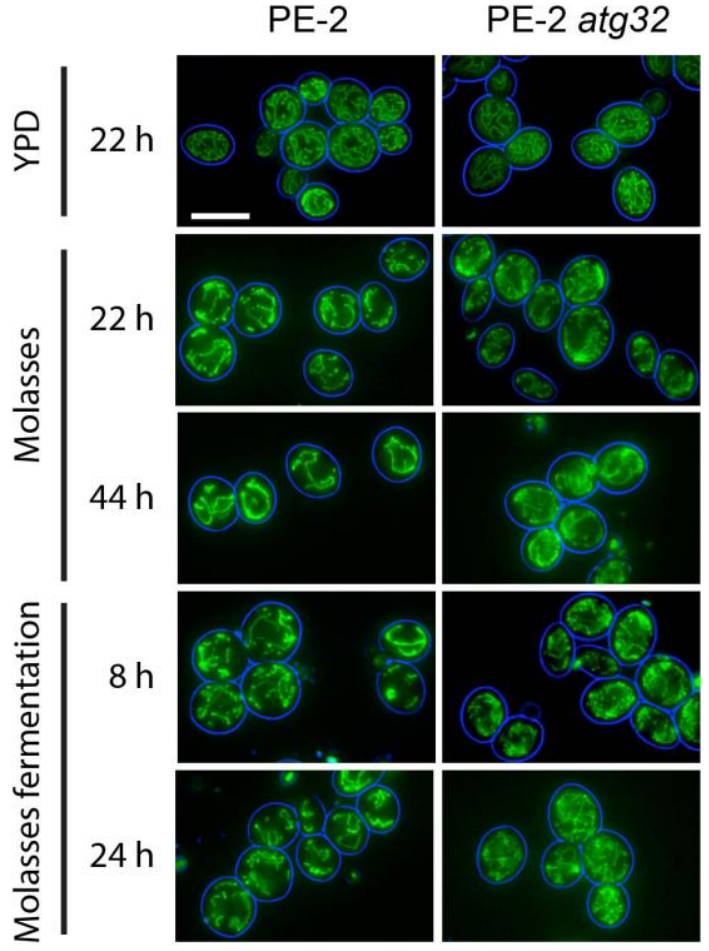


a

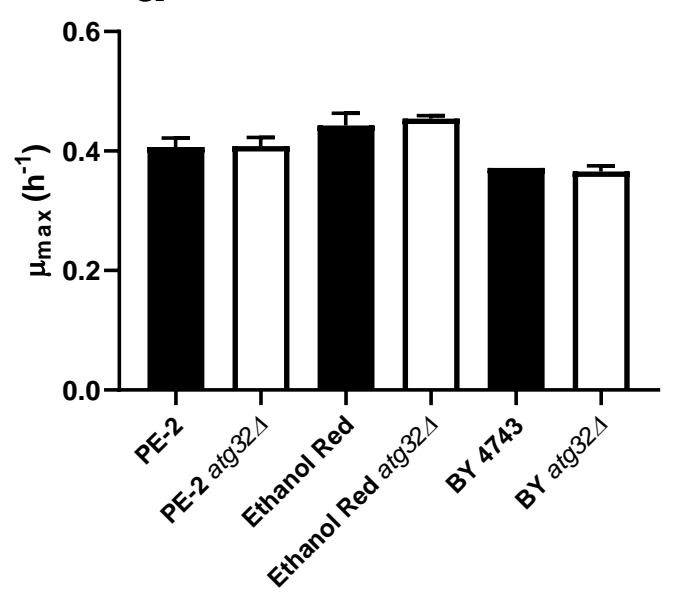

b

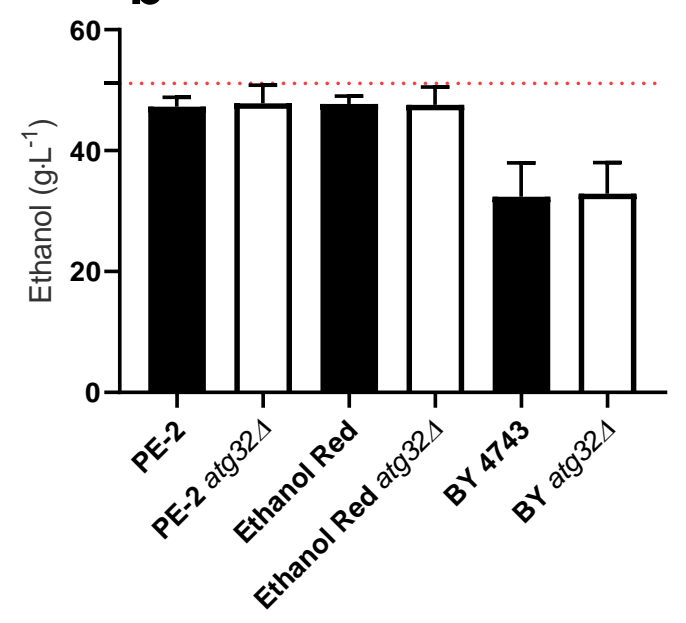

Figure 2 
a

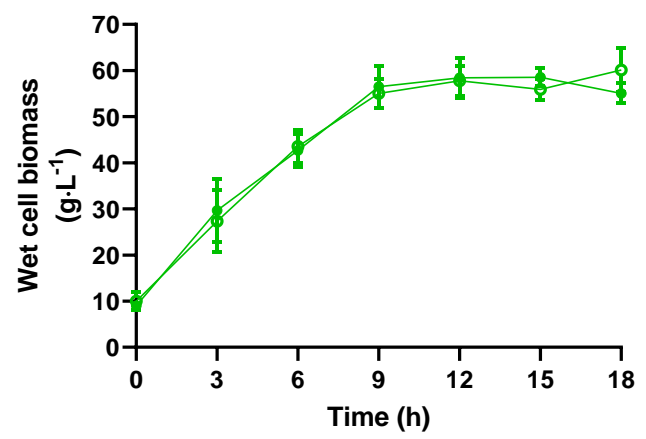

b

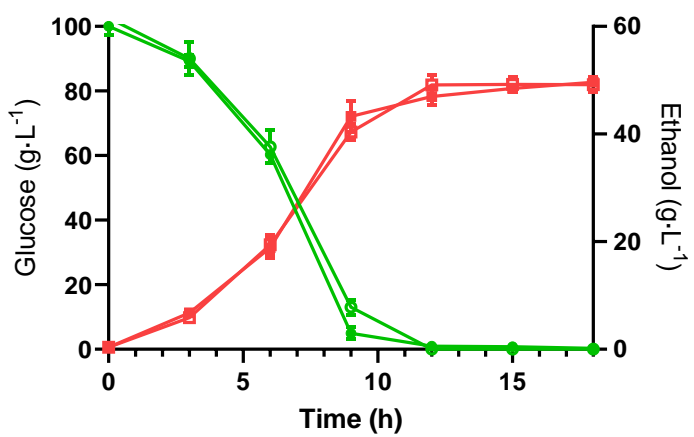

Figure 3 
a

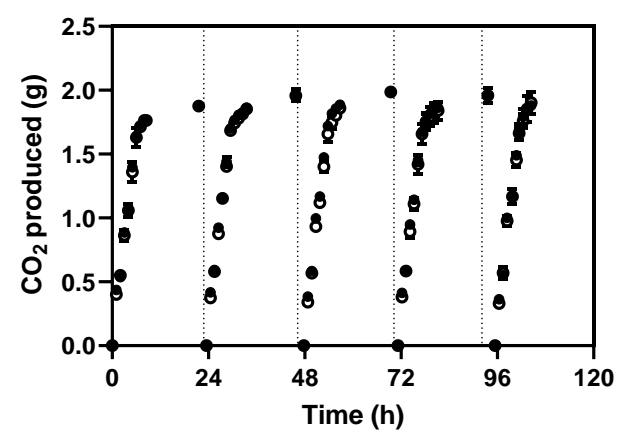

b

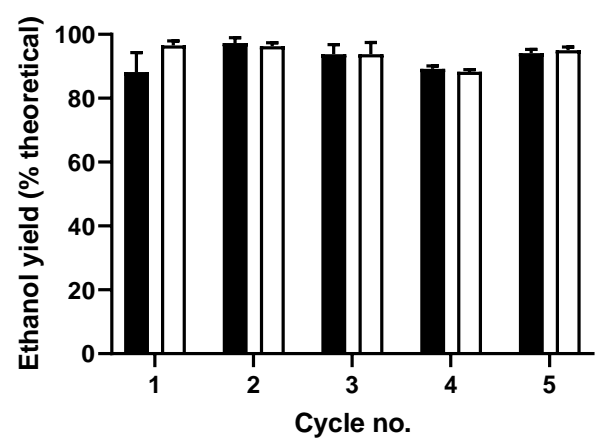

710

711

Figure 4

712 
a

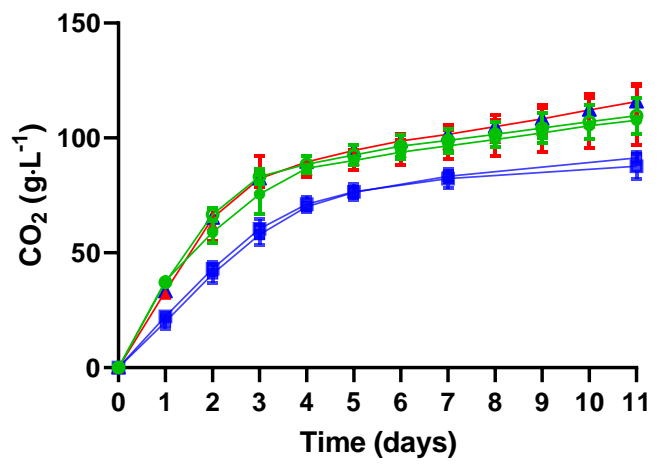

b

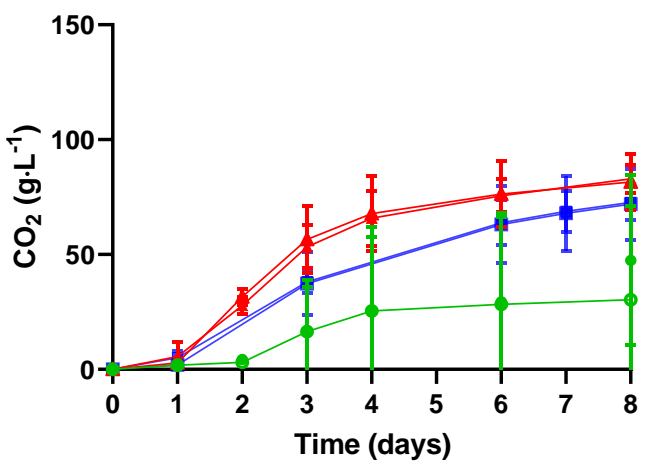

713

\section{$714 \quad$ Figure 5}


a

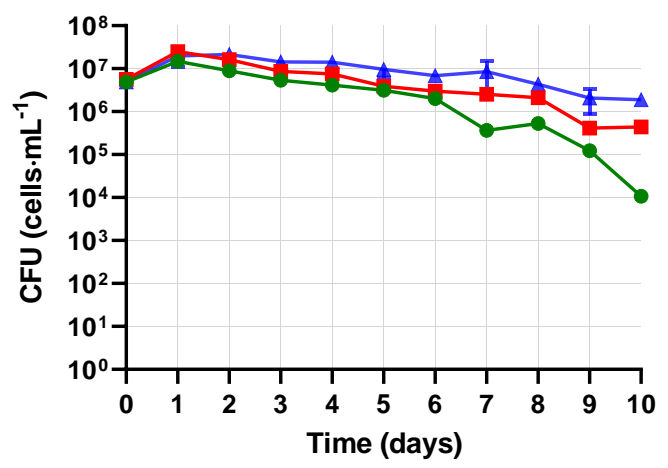

b

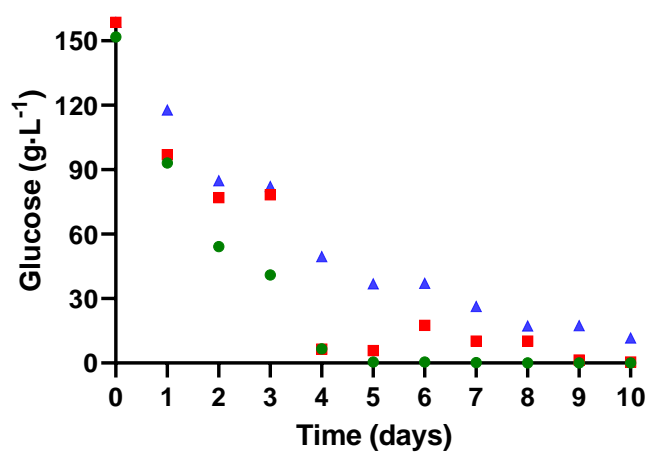

C

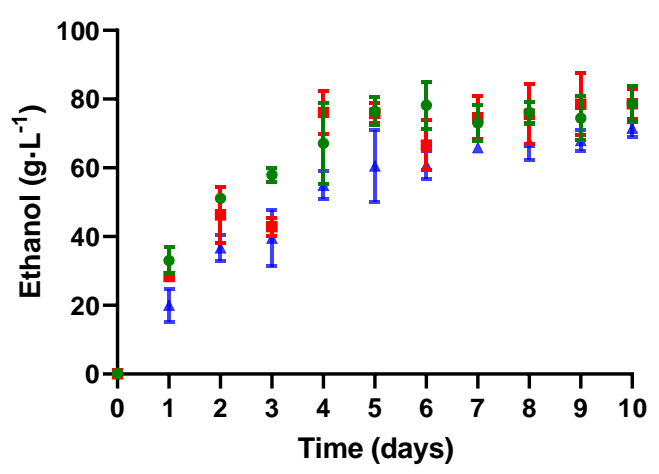

d

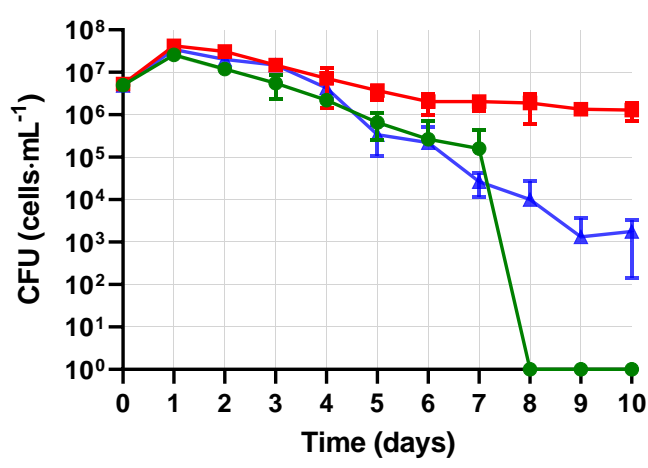

e

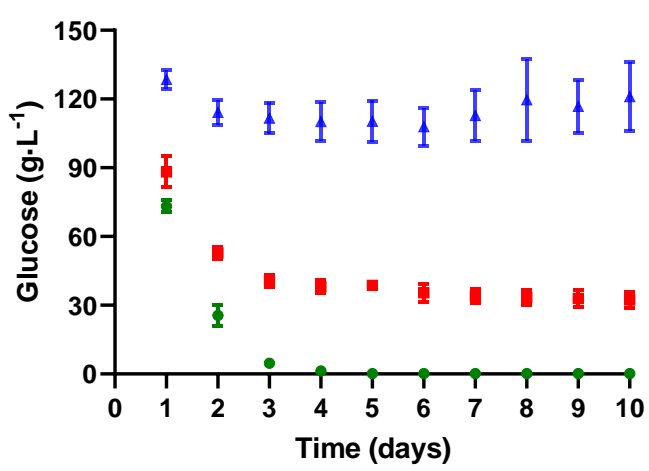

f

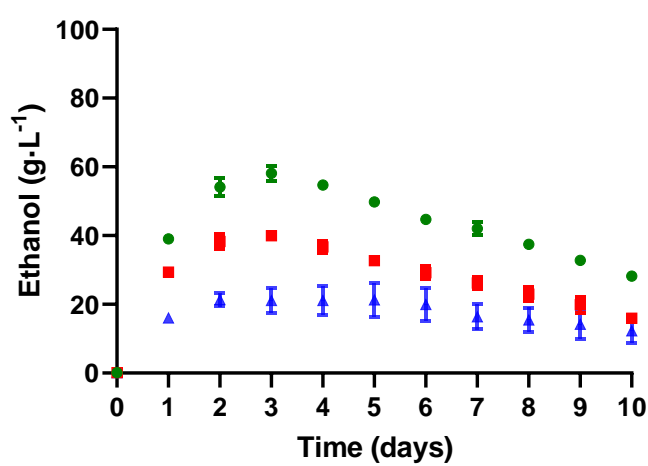

$717 \quad$ Figure 6 
718 Supplementary Material

719

720 Supplementary Figures

721 Supplementary Figure S1: a) glycerol b) biomass c) trehalose d) cell number e) mean

722 forward scatter (FSC) value for WT PE-2 and atg32 $\triangle$ S. cerevisiae in diluted molasses

723 medium in a scaled down and mimicked Brazilian fermentation process. Data represent the

724 mean and standard deviation of three technical replicates, but the experiment was performed

725 twice.

726 Supplementary Figure S2: CFU of WT and atg32 $\Delta$. cerevisiae in YPD after growth for 10

727 days in SC medium using $150 \mathrm{~g} \cdot \mathrm{L}^{-1}$ glucose for PE-2, Ethanol Red, and BY yeast.

728 Supplementary Figure S3: Spot assays of PE-2, Ethanol Red, and BY yeast in $\mathrm{pH}^{*}$ 2.5, $2 \%$

729 YPD and 20\% YPD. $(\mathrm{n}=2)$. ( ${ }^{*}$ For making $\mathrm{pH} 2.5$ YPD plates, the volume of sulphuric acid

730 needed to bring the $\mathrm{pH}$ of a known volume of standard YPD to 2.5 was measured; the acid

731 solution was filter sterilised and then aseptically added to YPD agar just before pouring onto

732 plates.) 
a

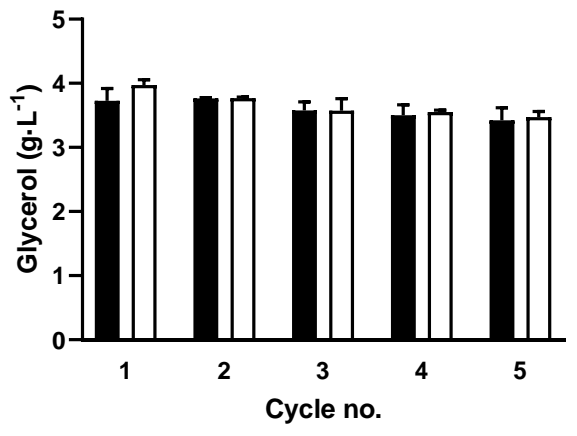

C

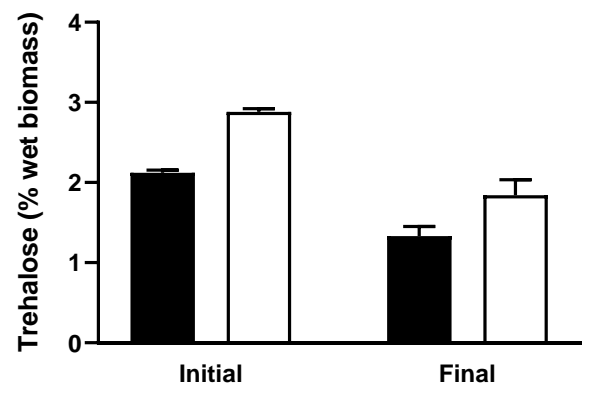

e

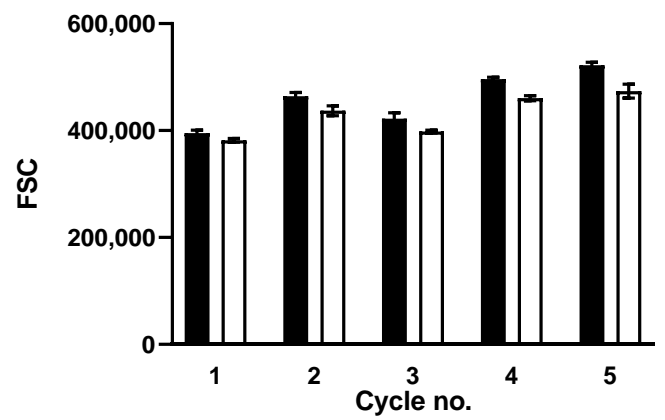

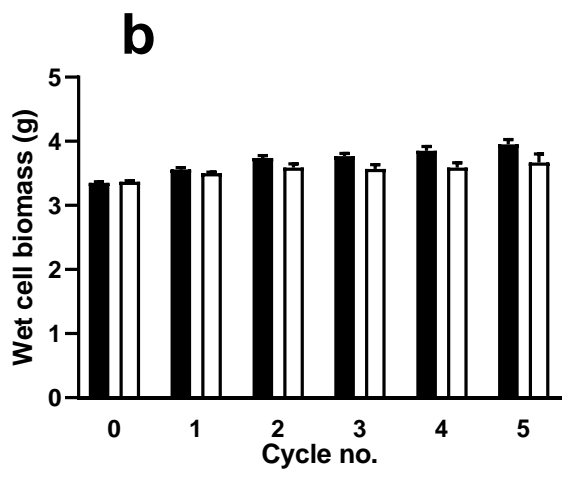

d

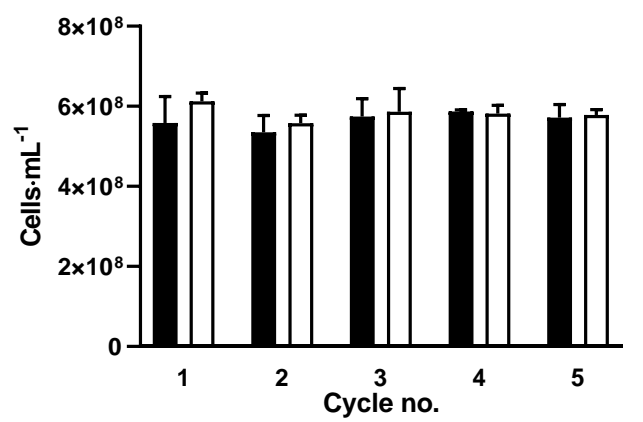

\section{Supplementary Figure S1}


PE-2

$(1: 50)$

PE-2 atg $32 \triangle$

$(1: 50)$

Ethanol Red

(1:1000)

Ethanol Red

$\operatorname{atg} 32 \Delta$

(1:1000)

BY

(1:1000)

BY atg32 $\triangle$

(1:1000)
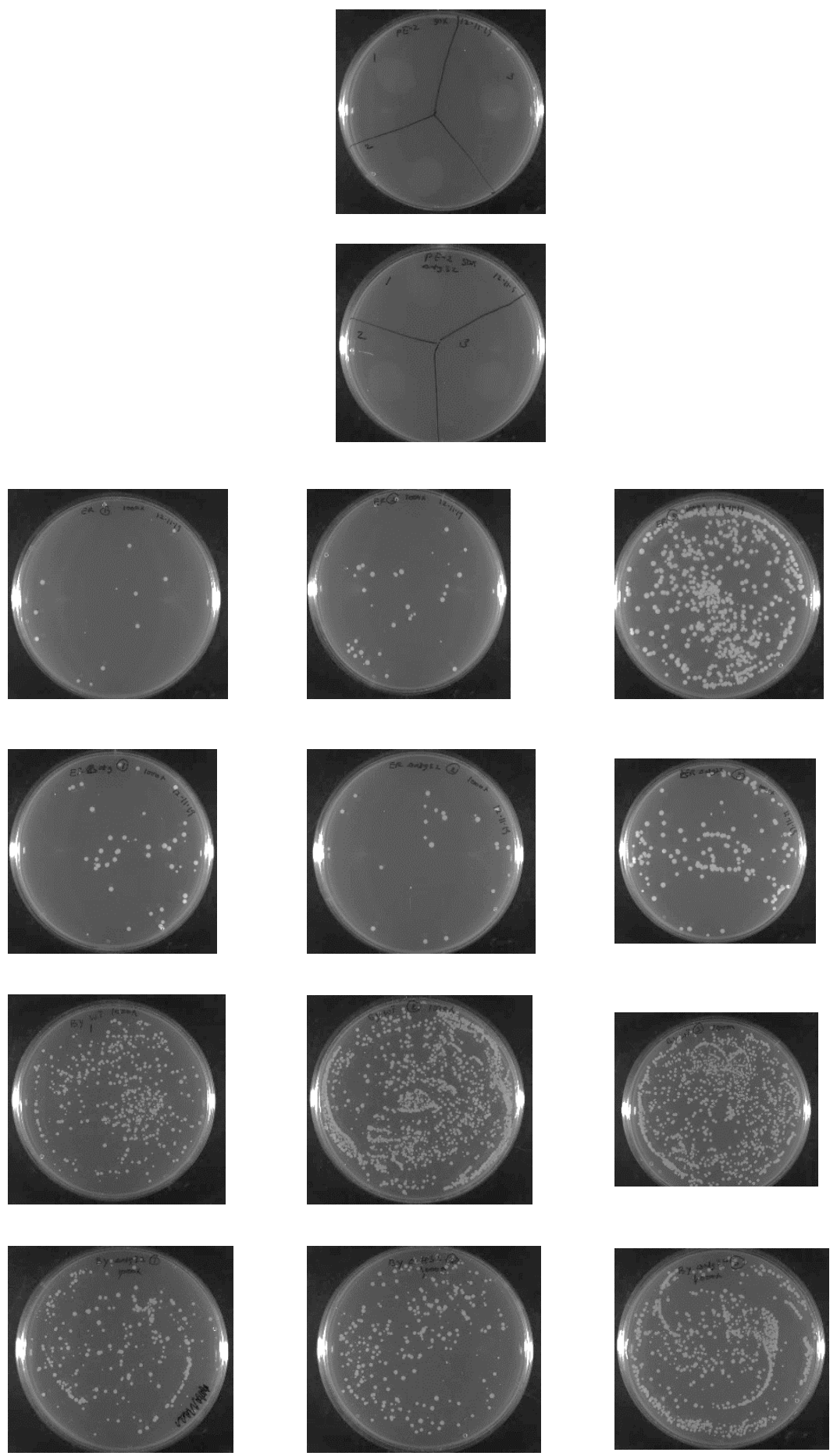

\section{Supplementary Figure S2}


$\mathrm{pH} 2.5$

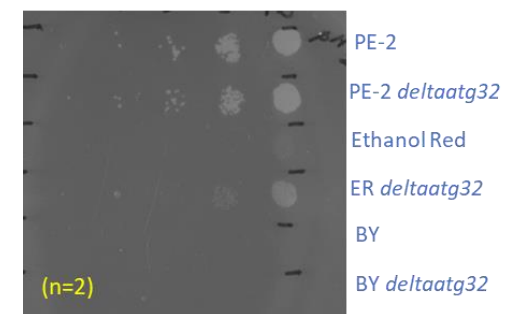

YPD

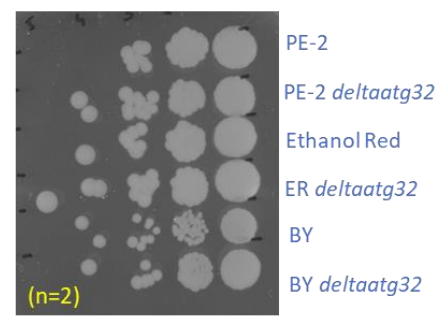

YP20D

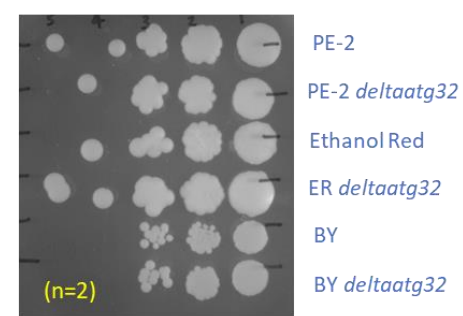

\section{Supplementary Figure S3}


743 Table S1: Primers used in this study

\begin{tabular}{|c|c|c|}
\hline Purpose & Name & Sequence $5^{\prime} \rightarrow 3^{\prime}$ \\
\hline $\begin{array}{l}\text { Amplification of pAG32, } \\
\text { pAG35 and p4339 upper } \\
\text { strand for } \boldsymbol{A} \boldsymbol{T G} 32 \text { deletion; } \\
\text { Forward primer }\end{array}$ & VIP3915 & $\begin{array}{l}\text { TGAAGTCCTAATCACAAAAGCAAAAAAAA } \\
\text { TCTGCCAGGAACAGTAAACATCAGCTGAA } \\
\text { GCTTCGTACGC }\end{array}$ \\
\hline $\begin{array}{l}\text { Amplification of pAG32, } \\
\text { pAG35 and p4339 for ATG32 } \\
\text { deletion; Reverse primer }\end{array}$ & VIP3916 & $\begin{array}{l}\text { TAGTAAAAAAGTGAGTAGGAACGTGTATG } \\
\text { TTTGTGTATATTGGAAAAAGGGCATAGGC } \\
\text { CACTAGTGGATCTG }\end{array}$ \\
\hline $\begin{array}{l}\text { Tagging Mdh1 with } \\
\text { GFP(S65T); Forward primer }\end{array}$ & VIP4045 & $\begin{array}{l}\text { AAACCTTGAAGAAGAATATCGAAAAGGG } \\
\text { TGTCAACTTTGTTGCTAGTAAAGCTGCAG } \\
\text { GTCGACGGATC }\end{array}$ \\
\hline $\begin{array}{l}\text { Tagging Mdh1 with } \\
\text { GFP(S65T); Reverse primer }\end{array}$ & VIP4046 & $\begin{array}{l}\text { TTTTTTTTTTTTTTTCCCTATTTTTCACTC } \\
\text { TATTTCTGATCTTGAACAATGCATAGGCC } \\
\text { ACTAGTGGATC }\end{array}$ \\
\hline $\begin{array}{l}\text { Diagnostic primer for gene } \\
\text { deletion forward }\end{array}$ & VIP1078 & CAGATCCACTAGTGGCCTATGC \\
\hline $\begin{array}{l}\text { Diagnostic primer for gene } \\
\text { deletion; reverse }\end{array}$ & VIP1079 & GCGTACGAAGCTTCAGCTG \\
\hline $\begin{array}{l}\text { Diagnostic primer for } \boldsymbol{A T G 3 2} \\
\text { gene deletion; forward }\end{array}$ & VIP3952 & AAAACACCAGCGAACAGCAG \\
\hline $\begin{array}{l}\text { Diagnostic primer for } \boldsymbol{A T G 3 2} \\
\text { gene deletion; reverse }\end{array}$ & VIP3953 & TTGAAGTCGTCGGAATACGC \\
\hline
\end{tabular}

745 Table S2: List of plasmids used in this study

\begin{tabular}{l|l|l}
\hline \hline Name & Relevant characteristics & Source \\
\hline pAG32 & HphMX & Euroscarf \\
\hline pAG35 & NatMX & Euroscarf \\
\hline pF339 & NatMX & $(21)$ \\
\hline pFA6a-GFP(S65T)-HIS3MX6 & GFP KanMX & $(23)$ \\
\hline
\end{tabular}

